PONTIFÍCIA UNIVERSIDADE CATÓLICA DO RIO DE JANEIRO

\title{
Marketing Sensorial e Sua Influência no Comportamento de Consumidores de Produtos de Beleza
}

\section{Mariana Oliveira Mattos}

Trabalho de Conclusão de CuRso

Centro de ClÊnCIAS SOcials - CCS

DEPARTAMENTO DE ADMINISTRAÇÃO

Graduação em Administração de Empresas 


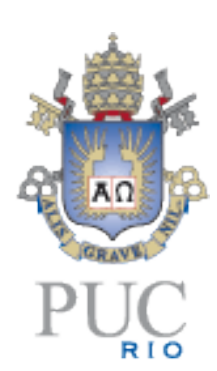

MARIANA OLIVEIRA MATTOS

\section{Marketing Sensorial e sua Influência no Comportamento de Consumidores de Produtos de Beleza}

Trabalho de Conclusão de Curso

Trabalho de Conclusão de Curso, apresentado ao programa de graduação em Administração da PUC-Rio como requisito parcial para a obtenção do titulo de graduação em Administração.

Orientador: Daniel Kamlot

Rio de Janeiro

Novembro de 2018. 


\section{Agradecimentos}

Primeiramente, agradeço aos meus pais pela oportunidade e apoio necessário nessa caminhada e ao meu irmão por todo o carinho de sempre.

Aos meus amigos, também futuros administradores, que caminharam sempre juntos a mim e dispostos a ajudar no que fosse preciso.

Ao orientador Professor Daniel Kamlot, pela atenção e disponibilidade durante o processo de elaboração deste estudo. 


\title{
Resumo
}

O presente trabalho analisa a influência do marketing sensorial no comportamento do consumidor de produtos de beleza no Rio de Janeiro. Como ponto de partida, foi estudado o mercado de beleza, o comportamento do consumidor e o conceito de marketing sensorial. $\mathrm{O}$ objetivo principal é identificar se a aplicação do marketing sensorial, tanto no ponto de venda quanto nos produtos, gera uma consequência a ponto de influenciar o comportamento de compra do consumidor de perfumes e cosméticos. Para isto, foi realizada uma pesquisa quantitativa com dois questionários, um online e o outro presencial a fim de entender a influência dos estímulos sensoriais.

Palavras- chave

Marketing Sensorial, Sentidos, Comportamento do Consumidor, Produtos de Beleza

\begin{abstract}
This paper analyzes the influence of sensory marketing on the consumer of beauty products in Rio de Janeiro. As a starting point, the beauty market, the consumer behavior and the concept of sensorial marketing, were analyzed. The primary objective is to identify if the use of sensory marketing, both at the stores and in the products, creates an impact that is able to influence the buying behavior of the consumer of perfumes and cosmetics. For this, a quantitative research was conducted with two questionnaires, one online and the other one in person, to understand the impact of sensory stimulation.
\end{abstract}

Key-words

Sensory Marketing, Senses, Consumer Behavior, Beauty Products 


\section{Sumário}

1.1. Introdução ao tema e ao problema do estudo 1

1.2. Objetivo do estudo 2

1.3. Objetivos intermediários do estudo 2

1.4. Delimitação e foco do estudo 3

1.5. Justificativa e relevância do estudo 3

1.6. Justificativa e relevância do estudo 4

1.7. O Mercado 4

1.8. Marketing sensorial no mercado de beleza 5

1.8.1. No ponto de venda

1.8.2. Nos produtos $\quad 6$

2 Revisão de literatura $\quad 8$

2.1. O processo de compra do consumidor 8

2.2. Atmosfera e imagem da loja 9

2.3. Percepção 9

2.4. Marketing sensorial 9

2.4.1. Visão 10

2.4.2. Olfato 11

2.4.3. Audição 12

3 Métodos e procedimentos de coleta e de análise de dados do estudo 13

$\begin{array}{ll}3.1 . & \text { Tipo de pesquisa } \\ & 13\end{array}$

3.2. Universo e amostra 13

3.3. Coleta de dados 14

3.4. Tratamento dos dados 15

3.5. Limitações do método 15

4 Análise de resultados 16

4.1. Perfil da amostra 16

4.2. Resultados do método $1 \quad 16$

4.3. Resultados do método 2

5 Conclusão 31

5.1. Aplicações gerenciais $\quad 32$

6 Referências Bibliográficas $\quad 33$

Anexo 1 - Questionário presencial $\quad 36$

Anexo 2-Questionário online $\quad 41$ 


\section{Lista de Quadros}

Quadro 1 - Onde os consumidores costumar comprar produtos de beleza 18

\section{Lista de Gráficos}

Gráfico 1 - O que chama mais atenção dos respondentes dentro de uma loja

Gráfico 2 - Motivo pelo qual o consumidor compra produtos de beleza

Gráfico 3 - Motivo pelo qual o respondente já desistiu de comprar em uma loja de beleza ..18

Gráfico 4 - Qual sentido acredita mais utilizar ao escolher um produto de beleza.....

Gráfico 5 - Influência da música sobre o comportamento de compra

Gráfico 6 - Influência de eventos com experimentações e música

Gráfico 7 - Importância de provar um perfume antes da compra .

Gráfico 8 - Importância de provar uma maquiagem antes da compra

Gráfico 9 - Quantidade de respondentes que conhecem o produto Délice de Poudre da

Bourjois

Gráfico 10 - Influência do aroma do produto no momento de compra

Gráfico 11 - Probabilidade de compra da máscara de hidratação L'Oreal Professionel..... .23

Gráfico 12 - Probabilidade de compra do hidratante labial regular Nivea .23

Gráfico 13 - Onde os consumidores costumam comprar produtos de beleza .24

Gráfico 14 - O que chama mais atenção dos respondentes dentro de uma loja .24

Gráfico 15 - Motivo pelo qual o consumidor compra produtos de beleza.

Gráfico 16 - Motivo pelo qual o respondente já desistiu de comprar em uma loja de beleza25

Gráfico 17 - Qual sentido acredita mais utilizar ao escolher um produto de beleza 26

Gráfico 18 - Influência da música sobre o comportamento de compra .26

Gráfico 19 - Influência de eventos com experimentações e música 27

Gráfico 20 - Importância de provar um perfume antes da compra .27

Gráfico 21 - Importância de provar uma maquiagem antes da compra 28

Gráfico 22 - Quantidade de respondentes que conhecem o produto Délice de Poudre da Bourjois

Gráfico 23 - Influência do aroma do produto no momento de compra .28

Gráfico 24 - Probabilidade de compra do hidratante labial de morango Nivea ..... .29

Gráfico 25 - Probabilidade de compra da máscara de hidratação Lola Cosmetics. 29 


\section{0 tema e o problema de estudo}

\subsection{Introdução ao tema e ao problema do estudo}

O culto ao corpo e à beleza é cada vez mais presente nas sociedades contemporâneas, impulsionado principalmente pela difusão da imagem perfeita pelas redes sociais, campanhas publicitárias e revistas voltadas para o público feminino. A preocupação com a imagem e estética se torna cada vez maior e a população brasileira não fica para trás. Na quarta posição do Ranking Mundial da Beleza (2017), atrás apenas dos Estados Unidos, Japão e China, segundo a Euromonitor International (empresa líder mundial em pesquisa em estratégias para os mercados consumidores) o país possui uma enorme força ao se tratar do culto aos cuidados pessoais.

A devoção do brasileiro à beleza corporal não é de hoje, mas uma pesquisa realizada pelo Serviço de Proteção ao Crédito (SPC Brasil) em 2016 revela que mesmo em tempos de crise como a atual, a população se mostra mais disposta a abrir mão de programas de lazer do que de seus produtos de beleza, sendo seis entre dez brasileiros pessoas preocupadas com a aparência externa.

Com uma expectativa de crescimento de em média 2,7\% por ano até 2020 e correspondendo a $7,1 \%$ do mercado mundial de beleza, segundo a Euromonitor (2017), o cenário do mercado no Brasil é bem favorável. Ainda que tenha apresentado baixos índices de crescimento nos últimos anos de forma geral, o setor obteve crescimento muito maior do que o restante da indústria. Além disso, alguns fatores como o envelhecimento da população e o aumento da expectativa de vida, que inspiram mais cuidados e investimentos para a manutenção da jovialidade, e o aumento do poder de compra da classe C, impulsionam ainda mais os bons resultados, de acordo com a Associação Brasileira da Indústria de Higiene Pessoal, Perfumaria e Cosméticos (ABIHPEC, 2017).

Além de todo o cenário positivo, é imprescindível notar que o comportamento do consumidor de produtos de beleza no país vem se modificando e, com isso, do ponto de vista do comércio varejista, os canais de venda também têm de se adaptar. Se antes a tendência era a venda do tipo porta a porta e/ou encomendar e comprar produtos no exterior, hoje já existem no país lojas que procuram revolucionar a experiência de compra do consumidor a fim de mantê-lo por mais tempo em loja e fidelizá-lo, visto que também existem as opções das lojas virtuais. O ponto de venda deixa de ser apenas o local físico destinado a compra, passando a oferecer muito mais do que apenas produtos, e a atender 
os desejos dos consumidores, que com o acesso a todo tipo de informação, demandam cada vez mais atenção especial à seus desejos.

Sendo assim, proporcionar a melhor experiência de compra para o cliente tornou-se o grande desafio das organizações, e utilizando-se dos cinco sentidos, ou seja, visão, audição, olfato, tato e paladar, grandes varejistas têm apostado em práticas de marketing sensorial.

O contexto acima leva à seguinte questão que servirá como ponto de partida para o presente estudo: de que forma as práticas de marketing sensorial influenciam no comportamento do consumidor de produtos de beleza?

\subsection{Objetivo do estudo}

O presente trabalho tem como objetivo identificar a influência da utilização do marketing sensorial em lojas e produtos de beleza no comportamento do consumidor de perfumes e cosméticos.

\subsection{Objetivos intermediários do estudo}

Buscando-se alcançar o objetivo final proposto para o presente estudo, os objetivos intermediário estão relacionados à análise do comportamento do consumidor de produtos de beleza, sendo eles:

$\checkmark$ Identificar os incentivos que compõem a tomada de decisão do consumidor de produtos de beleza.

Aqui procura-se entender o processo de compra do consumidor como os fatores que levam à escolha de uma marca específica em detrimento de outra.

$\checkmark \quad$ Identificar as práticas de marketing sensorial adotadas nas apresentações dos produtos.

Entender como marcas se utilizam do marketing sensorial na concepção dos produtos, dando exemplos.

$\checkmark \quad$ Identificar as práticas de marketing sensorial adotadas pela Sephora, um caso de sucesso em seu mercado. 
Pretende-se discriminar quais as práticas empregadas por uma empresa líder no mercado estudado, dando exemplos.

$\checkmark$ Analisar de que forma o marketing sensorial impacta especificamente na decisão final de compra do consumidor de perfumes e cosméticos.

Por fim, pretende-se analisar se as práticas têm realmente um resultado sobre o comportamento do consumidor.

\subsection{Delimitação e foco do estudo}

Dadas as diversas fontes em que poderiam ser coletados os dados sobre as práticas de marketing sensorial no mercado de beleza, este estudo usará como exemplo tanto práticas adotadas por lojas especializadas em beleza quanto por diversas marcas na elaboração dos produto final.

Em questão de análise do ambiente, será analisada apenas a empresa Sephora, pelo reconhecimento desta no mercado em que atua, excluindo outras lojas que possam oferecer os mesmos serviços e farmácias que também vendem esse tipo de produto. Embora ainda relevantes, lojas que não vendem exclusivamente produtos voltados à beleza não costumam abordar tanto quanto as demais as práticas de marketing sensorial no ambiente de loja.

Além disso, serão considerados apenas 3 dos 5 sentidos, sendo eles: visão, audição e olfato, uma vez que paladar e tato não exercem influência significativa no presente estudo.

\subsection{Justificativa e relevância do estudo}

O presente estudo é relevante para varejistas do ramo da beleza, uma vez que analisará a importância e eficiência do marketing sensorial no ponto de venda, além de destacar quais as práticas mais eficazes. Dessa forma, o estudo vai possibilitar o entendimento de táticas que podem ser aplicadas no ponto de venda visando ao aumento do número de vendas.

Também será útil para as marcas de mercado em questão, já que com os resultados espera-se entender a importância de alguns fatores como relevância da embalagem e odor no processo de escolha de compra do consumidor.

Com os resultados alcançados, também poderá ser útil para que empresas de marketing consigam identificar oportunidades de oferecer seus serviços para lojas que ainda não explorem tanto o lado sensorial. 


\subsection{Justificativa e relevância do estudo}

O presente estudo é relevante para varejistas do ramo da beleza, uma vez que analisará a importância e eficiência do marketing sensorial no ponto de venda, além de destacar quais as práticas mais eficazes. Dessa forma, o estudo vai possibilitar o entendimento de táticas que podem ser aplicadas no ponto de venda visando ao aumento do número de vendas.

Também será útil para as marcas de mercado em questão, já que com os resultados espera-se entender a importância de alguns fatores como relevância da embalagem e odor no processo de escolha de compra do consumidor.

Com os resultados alcançados, também poderá ser útil para que empresas de marketing consigam identificar oportunidades de oferecer seus serviços para lojas que ainda não explorem tanto o lado sensorial.

\subsubsection{Mercado}

O mercado de produtos de beleza pode ser avaliado como que, em termos de vendas, quase constante durante os altos e baixos da economia. Ainda que em tempos de crise a tendência seja diminuir o consumo de produtos que possam ser considerados «supérfluos , como os de cuidados e higiene pessoal, alguns fatores explicam o crescente aumento nas vendas mundialmente, sendo eles: o contínuo uso pelas mulheres, aumento da utilização por homens, crescente tendência da venda online e o envelhecimento da população aliado ao aumento da expectativa de vida, segundo relatório da Orbis Research (2018).

Em 2017, o mercado foi avaliado em $\$ 523,43$ bilhões de dólares mas a expectativa é que cresça em média $50 \%$ até 2023 , de acordo com a mesma fonte, além de ter apresentado um crescimento de em média $3 \%$ ao ano durante os últimos 10 anos, segundo artigo de 2017 da Women`s Wear Daily (WWD), jornal comercial da indústria da moda.

O mercado é dividido entre seis principais players sendo eles por ordem de maior a menor share de mercado: a francesa L'Oréal, a britânica-neerlandesa Unilever, as americanas Proctor \& Gamble e Estée Lauder, a japonesa Shiseido e a também francesa Coty (WWD, 2017). Além disso, é dividido em seis categorias, sendo a maior delas e correspondendo a $37 \%$ a de cuidados com a pele, seguido por cuidados com o cabelo com $22 \%$, maquiagem com $19 \%$, perfumes com $12 \%$ e produtos de higiene pessoal com $10 \%$ (WWD, 2017).

Considerando o volume de vendas por regiões do globo, o maior número está concentrado na Ásia, com 37\%, seguido pela América do Norte, Europa Ocidental, América Latina, Leste Europeu e por fim África e Oriente Médio que juntos corresponderam a 3\% das 
vendas do ano de 2016 (WWD, 2017). Das Américas, logo atrás dos Estados Unidos, o Brasil é o país que mais se destaca.

Conforme mencionado anteriormente, o mercado de beleza no país é um dos maiores do mundo, ocupando atualmente a quarta posição no Ranking Mundial da Beleza e com fortes indícios de retornar ao terceiro lugar como costumava ocupar antes da crise, de acordo com a Euromonitor (2017). Por aqui, a brasileira Natura \& Co, marca detentora da Natura, Aeso e The Body Shop, lidera o mercado de produtos de beleza e cuidados pessoais, com participação de $11,7 \%$. Outros principais players são a já mencionada anteriormente como uma das líderes mundiais, Unilever, com 11,1\% e a também brasileira O Boticário, na terceira posição, com $10,8 \%$ do mercado. Ao tratar-se exclusivamente do mercado de cosméticos, a americana Avon é a líder, com $24,4 \%$ de participação de mercado, seguida pela Boticário, que vem crescendo expressivamente com a aquisição da marca Vult, e a Natura (Euromonitor, 2017).

O país também tem espaço para as marcas estrangeiras de cosméticos com loja própria, como a canadense MAC, a americana NYX e a francesa L'Occitane au Brésil. Das multimarcas de produtos de beleza, destacam-se a The Beauty Box, pertencente ao Grupo Boticário, Época Cosméticos com muita força no e-commerce e a grande referência no mercado mundial, Sephora.

\subsection{Marketing sensorial no mercado de beleza}

\subsubsection{No ponto de venda}

Pelo mundo existem diversas lojas especializadas em beleza e por isso é importante que as mesmas consigam se diferenciar frente às demais para conquistar seu espaço no mercado. Criada na França em 1979 por Dominique Mandonnaud, a Sephora é uma referência no mercado em que atua e surgiu com o intuito de revolucionar o modo de vender perfumes, que até então era feito por lojas de departamento sem qualquer tipo de atendimento personalizado, mantendo os produtos dispostos nas prateleiras sem destaque. Mandonnaud então cria um modelo que não só tira os produtos de beleza das prateleiras, mas os coloca no centro do negócio. Com a Sephora, os consumidores passaram a circular pela loja, como em um supermercado, tendo total liberdade para experimentar, sentir e testar os produtos. Assim, é estabelecido que serve como exemplo adequado ao uso do marketing sensorial em seu setor de atuação.

Todas as lojas possuem ferramentas com o intuito de revolucionar a experiência do consumidor no seu ponto de venda. Quase todas elas possuem, por exemplo, o Beauty Bar, onde são oferecidos serviços rápidos e gratuitos de maquiagem, além do Brow Bar, que é 
focado nas sobrancelhas. O Color IQ, ferramenta online desenvolvida em parceria com a Pantone Color Institute, permite identificar as opções de maquiagem e acessórios que combinam com o tom de pelo do consumidor, e o smart mirror é o espelho inteligente de tecnologia aumentada que mostra como a maquiagem fica no cliente em tempo real, sem precisar carregar uma foto de si próprio. Juntamente a diversas outras experiências oferecidas pelas marca, a companhia também aplica o conceito do marketing sensorial nas suas lojas.

O visual da mesma é algo que por si só chama a atenção do consumidor. A predominância do preto no interior cria a ideia de um ambiente chique e glamuroso. A disposição dos produtos, escolha de cores e criação dos corners de cada uma das marcas vendidas também são dispostos de forma a facilitar o processo de compra. A dimensão sonora também é algo importante, uma vez que o consumidor lida com os sons de maneira inconsciente durante o processo de compra. Logo, a marca utiliza músicas modernas, que permitem atrair o seu público alvo, ao mesmo tempo em que apresenta músicas de natureza lenta para encorajar os consumidores a caminhar pelos corredores (Retail Dive, 2017).

A questão do aroma do ambiente também é controlado, já que tem influência importante no comportamento de seus clientes. Para evitar que os diversos aromas dos perfumes testados se misturem, possui um forte sistema de ventilação em seus pontos de venda. Com o tato, ela não se limita apenas à escolha do material e à forma do produto, mas, segundo uma reportagem da escola de marketing francesa ISEG (2017), até o tapete vermelho presente nas lojas é feito de um material mais macio, com o intuito de passar leveza e fluidez para o consumidor.

Ainda que neste capítulo tenha sido analisado o caso Sephora como exemplificação do marketing sensorial em lojas de beleza, fato é que a utilização do marketing sensorial como forma de atrair o consumidor está cada vez mais presentes no varejo.

\subsubsection{Nos produtos}

Ainda que a questão do ambiente exerça influência no comportamento do consumidor, dificilmente algo chama mais a atenção do cliente do que a embalagem do produto em si. $\mathrm{Na}$ maioria das vezes, o produto só é avaliado após a compra e é por isso que as embalagens têm deixado de ser apenas o envoltório e recipiente do produto para se tornar peça chave de convencimento de compra do consumidor (Brasil Escola, 2017).

É cada vez mais comum encontrar marcas, incluindo brasileiras, apostando em um storytelling na embalagem, como as de cabelo Salon Line e Lola Cosmetics fazendo com que o produto consiga se destacar por si só independente do ambiente inserido, ou seja, tanto em uma farmácia quanto em uma loja especializada. No quesito maquiagem, podem 
ser citadas como exemplo as marcas Benefit Cosmetics, Tarte, Too Faced, Glossier, Soap \& Glory entre outras.

O odor do produto, ainda que seja algo pessoal, também é uma aposta uma vez que consegue despertar diversas sensações no consumidor, conforme mencionado anteriormente. O case de sucesso da rede de rosquinhas e café Dunkin'Donuts na Coreia do Sul exemplifica bem essa situação. Ainda que a cadeia de lanchonetes seja um serviço, ela não ficou para trás ao utilizar o marketing sensorial para despertar a atenção dos clientes. A ação consistiu na aplicação de aromatizadores em ônibus que soltavam um odor de café toda vez que tocava o anúncio da empresa e teve como consequência um aumento de $29 \%$ das vendas. Não é à toa também que diversas maisons de perfumes criam uma edição especial para o verão, com normalmente fragrâncias mais frescas, como é o caso do clássico 212 de Carolina Herrera e sua versão 212 Summer.

Atualmente, até mesmo maquiagens têm recebido aromatizantes, como é o caso das maquiagens da Too Faced. A paleta de sombra Sweet Peach Eyeshadow Palette tem cheiro de pêssego, enquanto a The Chocolate Bar tem cheiro de chocolate, assim como o pó bronzeador Délice de Poudre, da Bourjois, que recebe forma e cheiro que remetem ao chocolate. Já a Glossier possui uma coleção de batons com sabores e odores diversos, entre eles coco e o exótico Birthday Cake, que remete ao sabor de bolos de aniversário.

Logo, unindo o odor a outras características, como forma e embalagem e até mesmo sons, grandes marcas têm conseguido cada vez mais captar a atenção do seu consumidor levando-os a fazer exatamente o que se espera: comprar mais. 


\section{Revisão de literatura}

Neste capítulo são apresentados e discutidos aspectos conceituais e estudos relacionados ao tema e estudo em investigação e que servirão de base para a análise realizada.

Esta seção está dividida em 4 partes que abordam, respectivamente, o conceito do processo de compra segundo Solomon (2016) e as questões de atmosfera e imagem de loja segundo e Keller (2009), Peter e Olson (2009), Churchill e Peter (2005) e Solomon (2016).

$\mathrm{Na}$ terceira seção é analisada a questão de percepção do consumidor segundo Solomon (2016) sendo, por fim, apresentada a abordagem de Solomon (2016) e outros autores de artigos sobre o marketing sensorial.

\subsection{0 processo de compra do consumidor}

O processo de compra de um consumidor é dividido em cinco etapas: reconhecimento do problema, busca de informações, avaliação de alternativas, escolha do produto e avaliação pós compra, de acordo com Solomon (2016).

A primeira etapa acontece quando experimenta-se uma diferença significativa entre o estado das coisas atual e algum estado que se deseja alcançar. Consequentemente, é criada uma nova necessidade ou um problema. Após identificar essa necessidade, o consumidor passa à segunda etapa, em que busca dados adequados a fim de tomar uma decisão. Tais dados serão adquiridos através de fontes pessoais, comerciais, públicas e/ou experimentais e a quantidade de influência dessas fontes de informação varia de acordo com o comprador e a categoria do produto.

Em seguida, o consumidor chega ao ponto da avaliação das alternativas, no qual vai fazer uma comparação dentre as opções em potencial, podendo avaliar alguns fatores como benefícios e preços. Com a decisão tomada, o consumidor escolhe o produto que mais the convém, partindo para a avaliação pós-compra, em que será avaliado o resultado e fechando o ciclo de compra do consumidor. 


\subsection{Atmosfera e imagem da loja}

A loja é o primeiro contato que o consumidor tem com a marca escolhida e por isso precisa despertar interesse e incentivar os vários estágios do processo de compra do consumidor. Segundo Kotler e Keller (2009), o ambiente da loja é um aspecto importante, pois cada uma deve incorporar um ambiente planejado que seja adequado ao mercado-alvo e que consequentemente atraia clientes, favorecendo as compras nos estabelecimentos.

Peter e Olson (2009) acreditam que a imagem da loja é aquilo que os consumidores pensam sobre determinada loja, e isso inclui suas percepções e atitudes com base no marketing sensorial, que será explicado melhor no ponto 2.6. Churchill e Peter (2005) complementam que tais percepções se baseiam nas características físicas, nas mercadorias, nos preços, na propaganda, nos vendedores e incluem também estados emocionais.

Outra relevante influência sobre o comportamento do consumidor no local de venda é a atmosfera, ou seja, os fatores como arquitetura, iluminação e layout que chamam a atenção do cliente e estimulam as vendas. Solomon (2016) afirma que a projeção consciente do espaço e de suas várias dimensões pode despertar determinados efeitos nos consumidores, influenciando em suas compras.

\subsection{Percepção}

Visando conquistar o consumidor a todo custo, profissionais de marketing lançam a cada minuto estímulos externos, ou inputs sensoriais, a fim de provocar sensações no consumidor. "Sensação se refere à resposta imediata dos receptores sensoriais (olhos, ouvido, boca, dedos, pele) a estímulos básicos como luz, cor som, odores e texturas" (SOLOMON, 2016, p.174). Seguido da sensação, chegamos à percepção, processo de três estágios que traduz estímulos em significados e no qual as pessoas selecionam, organizam e interpretam tais sensações.

O primeiro estágio é a exposição, que ocorre quando um estímulo penetra na gama de receptores sensoriais de uma pessoa. Em seguida, vem a atenção, que se refere ao grau com que a atividade de processamento é dirigida a um estímulo especifico. Por fim, chegase à interpretação dos estímulos recebidos, normalmente interpretados de acordo com padrões aprendidos e expectativas.

\subsection{Marketing sensorial}

Marketing sensorial é um conceito que surgiu na Inglaterra a partir dos estudos de neuromarketing. Segundo Benites (2016), ele utiliza como base o estudo dos cinco sentidos 
e as estratégias de como empregar esses recursos para marcas e lojas através da persuasão das pessoas em ambientes de compras. Solomon (2016) acredita que é o elo entre nossos sentidos e as experiências com os produtos, ou seja, é uma tática em que as empresas buscam criar vantagem competitiva através do estímulo aos cinco sentidos. Filser (2003) apud Teixeira e Barbosa (2008) cita que

é o conjunto de variáveis de ações controladas pelo produtos e/ou distribuidor para criar ao redor dos produtos ou serviços uma atmosfera multissensorial específica, seja por meio das características do produto/serviço, seja através da comunicação a seu favor, seja através do ambiente do ponto de venda (FILSER, 2003 apud TEIXEIRA e BARBOSA 2008, p.4)

O marketing sensorial surge com o intuito de preencher as lacunas deixadas pelo marketing tradicional, no qual a decisão de compra do consumidor passa a ser analisada em um parâmetro mais profundo. Ela deixa de ser analisada como resultado de avaliação das características funcionais do produto, comparação e escolha de acordo com suas necessidades e passa a ser vista com uma influência de experiências internas. Tais experiências têm dimensões sensoriais, emocionais, cognitivas, comportamentais e racionais, indo muito além da apenas funcionalidade (KOEHL apud TEIXEIRA E BARBOSA, 2008).

Em uma entrevista concedida à revista Pequenas Empresas \& Grandes Negócios em 2012, Marcelo D`Emidio, pró-reitor de graduação da ESPM, afirma que o conceito de marketing sensorial foi adotado no Brasil por volta de 2005, primeiramente em lojas conceito, ou seja, aquelas que têm como objetivo reforçar a identidade da marca de uma forma diferente, como através de experiências, por exemplo. A partir dos resultados obtidos, varejistas viram as vantagens de aplicar essas técnicas em pontos de venda convencionais.

Ter bons produtos na vitrine não é mais o suficiente para atrair a atenção do consumidor e por isso o apelo a tais sentidos é essencial, visto que a percepção do cliente é formada em uma relação direta com a conexão entre ele e o ambiente inserido. É necessário gerar uma experiência, permitindo que assim os clientes mantenham as marcas ou os ambientes na memória.

\subsubsection{Visão}

É pela visão que ocorre a maior parte das estratégias de marketing sensorial. De acordo com Blessa (2006), ela proporciona aos consumidores mais informações do que qualquer outro sentido, sendo um importante meio de explorar sua percepção sobre o 
ambiente. Consequentemente, torna-se o sentido mais responsável por direcionar as decisões dos clientes no momento de compra.

Em relação ao produto em si, a embalagem tem suma importância uma vez que acrescenta valor ao produto. Além de distinguir o produto de seu concorrente, ela é capaz de chamar a atenção do consumidor a metros de distância e por isso as marcas têm investido cada vez mais no storytelling das embalagens, buscando responder aos desejos e necessidades dos clientes.

Fatores como iluminação, arquitetura e layout da loja também impactam desde o primeiro momento. O esquema de luz utilizado tem capacidade tanto para estimular as vendas quanto para relaxar o consumidor. Além disso, a aparência e o padrão da distribuição dos produtos, além da própria distribuição do sortimento pela loja, podem encantar ou desestimular o cliente em poucos minutos. Os próprios móveis escolhidos para a exposição e decoração têm impacto sobre ele.

O esquema de cores escolhido também tem esse efeito, uma vez que faz parte do visual do ambiente físico e desempenha um papel importante na formação de humor e percepção do cliente. Cores quentes, por exemplo, têm o poder de atrair clientes e estimular decisões rápidas, já as cores frias tendem a relaxar o consumidor (SOLOMON, 2016).

A forma com que os produtos estão dispostos nas seções e nas prateleiras, com uma organização de cores e seguindo um parâmetro também faz muita diferença. Numa loja de beleza, por exemplo, a simples falta dos chamados testers, ou seja, provadores, na estante podem impactar numa venda, uma vez que, para o consumidor, a ausência deles pode trazer uma aparência de descuido na organização dos produtos, além de impedir a experimentação do produto antes da compra.

\subsubsection{Olfato}

Ainda que o sentido humano do olfato seja muito menos desenvolvido do que os dos animais, um simples aroma pode trazer à tona milhares de sensações, podendo despertar emoções ou criar sensações de serenidade, conforme Solomon (2016) afirma. Os aromas têm a capacidade de influenciar no estado de espírito das pessoas e isso ocorre, pois processamos sugestões de odores no sistema límbico, lugar onde as emoções imediatas são vivenciadas.

Aproveitando-se disso, ambientes de consumo fazem uso de odores distintos com o intuito de influenciar e atrair potenciais clientes. Sendo assim, o aroma pode ser dividido em duas categorias: o cheiro do ambiente e o do próprio objeto de consumo (SOLOMON, 2016). 
No ambiente geral, ele pode despertar sensações que aumentem a vontade do cliente de entrar na loja ou de consumir algo especifico, como ocorre em restaurantes e padarias, por exemplo. Já no objeto, pode estar presente em uma peça de couro que pode remeter a uma memória mais antiga ou uma simples maquiagem aromatizada.

\subsubsection{Audição}

Parecido com o aroma, a música e outros sons afetam diretamente os sentimentos e o comportamento das pessoas, e sua resposta emocional pode estimular diversos sentimentos, sejam bons ou ruins.

Além disso, o som do estabelecimento é capaz de influenciar o seu consumidor, uma vez que uma loja com um som agitado, por exemplo, demonstra a um senhor de idade que provavelmente suas necessidades não serão atendidas neste lugar. Um som alto pode criar uma atmosfera otimista e agitada, enquanto um som mais baixo passa uma ideia e sensação de tranquilidade. Dessa forma, é de extrema importância que o som do estabelecimento seja adequado ao tipo de público que se pretende atingir. 


\section{Métodos e procedimentos de coleta e de análise de dados do estudo}

Este capítulo pretende informar sobre as diversas decisões acerca da forma como a pesquisa foi realizada.

Está dividido em cinco seções que informam, respectivamente, sobre as etapas de coleta de dados da pesquisa realizada, sobre as fontes de informação selecionadas para coleta de informações nesta pesquisa. Na sequência, informa-se sobre os processos e instrumentos de coleta de dados realizados em cada etapa, com respectivas justificativas, sobre as formas escolhidas para tratar e analisar os dados coletados e, por fim, sobre as possíveis repercussões que as decisões sobre como realizar a pesquisa impuseram aos resultados assim obtidos.

\subsection{Tipo de pesquisa}

O tipo de pesquisa utilizado neste estudo foi a descritiva, com o objetivo de proporcionar esclarecimento e compreensão sobre a influência do marketing sensorial no comportamento de consumidores de produtos de beleza.

Segundo Zikmund (2006), o principal objetivo da pesquisa descritiva é descrever as características de uma população ou de um fenômeno. Malhotra (2006) complementa que é um tipo de pesquisa conclusiva que tem como principal objetivo a descrição de algo, sendo normalmente características ou funções do mercado.

Para a presente pesquisa, criou-se um questionário para coletar respostas do público feminino relacionadas a seu comportamento de compras de produtos de beleza, a fim de alcançar o objetivo de estudo.

\subsection{Universo e amostra}

O universo do estudo engloba toda a população frequentadora de lojas de beleza e/ou consumidoras de tais produtos no Brasil. O tipo de amostragem utilizado foi a não probabilística por conveniência, que aborda pessoas que estão mais convenientemente disponíveis à pesquisadora. 


\subsection{Coleta de dados}

Os dados foram coletados através de dois tipos de questionários, instrumento de coleta de dados composta por um determinado número de questões apresentadas por escrito às pessoas (GIL, 1999), um feito online e um feito presencialmente. Ambos foram elaborados a partir de questões fechadas que foram apresentadas aos respondentes com um conjunto de alternativas de respostas para serem selecionadas de acordo com sua experiência e/ou ponto de vista.

A diferença entre eles se deu na escolha das imagens utilizadas e no método de pesquisa utilizado, podendo ser online ou presencial. A ferramenta de pesquisa utilizada para a elaboração do questionário online foi o software Qualtrics, através de um link distribuído pelo Whatsapp visando alcançar o maior número de respostas. Com o objetivo de identificar a influência da utilização do marketing sensorial nos produtos de beleza e testar, mais especificamente, a visão, foram utilizadas imagens diferentes de produtos com a mesma função, uma máscara de hidratação capilar. Na pesquisa online, utilizou-se uma máscara da L’Oreal Professionel, marca consolidada no mercado de beleza que traz uma embalagem mais sóbria e sem muitos detalhes, enquanto na pesquisa física o produto escolhido foi O Poderoso Cremão da Lola Cosmetics, com uma embalagem rica em detalhes e explicativa. Além disso, no questionário online utilizou-se a imagem de um hidratante labial Nivea original enquanto no impresso o hidrante labial, também da mesma marca, possuía odor e sabor de morango.

Ademais, por se tratar de uma pesquisa com o objetivo de testar o impacto sensorial que não consegue ser medido por completo online, o questionário presencial possuía uma essência de morango nas folhas de papel, relacionada a um dos produtos exibidos na pesquisa com o objetivo de testar se o odor influenciaria nas respostas.

$\mathrm{Na}$ primeira parte do questionário buscou-se entender o comportamento de compra de consumidores de produtos de beleza no geral. Nesse momento foi questionado o que chama mais atenção do consumidor dentro de uma loja, onde mais se costuma comprar produtos voltados à beleza, o motivo pelo qual se compra tais produtos e o motivo de entrar em tais lojas.

$\mathrm{Na}$ segunda parte testa-se a relação do marketing sensorial no ambiente, com questões como motivos que já impediram a compra em um loja como a falta de iluminação, música alta e cheiro forte, se o tipo de música tocada influencia no comportamento de compra, quais dos cinco sentido acredita-se mais ser utilizado ao escolher uma maquiagem e também a influência de eventos e experimentações em lojas.

Por fim, as perguntas são direcionadas aos produtos em si, questionando o que mais importa para o consumidor em uma maquiagem, como preço ou embalagem, por exemplo, e 
a importância de se ter um provador disponível na compra de um perfume e uma maquiagem. Além disso, foram usados produtos já existentes como exemplos, questionando a probabilidade de compra ou não de certos produtos, além da familiaridade com um produto que contém odor, a fim de entender se a compra dele teve relação com seu aroma.

\subsection{Tratamento dos dados}

O tratamento do dados segue uma abordaram quantitativa. Para se chegar ao objetivo principal do estudo utilizou-se a tabulação, método que se refere à organização ordenada dos dados em uma tabela, que diz ao pesquisador com que frequência cada resposta ocorre (ZIKMUND, 2006). Também foi utilizada a tabulação cruzada, que descreve duas ou mais variáveis simultaneamente e a estatística descritiva (MALHOTRA, 2006).

\subsection{Limitações do método}

Conforme mencionado anteriormente, o instrumento de pesquisa utilizado foi 0 questionário, parte online e parte presencial. O uso do levantamento via Internet tem ganhado popularidade em razão dos baixos custos, além da rapidez das respostas (MALHOTRA, 2006). No entanto, possuí algumas limitações.

O questionário online impede o auxilio em caso de dúvidas, o que pode impactar na sua objetividade, uma vez que itens podem ter significados diferentes para cada pesquisado, conforme Gil (1999) apresenta.

Em relação ao questionário presencial, as limitações são referentes à amostra, uma vez que por todos os respondentes pertencerem à mesma universidade, pode haver certa tendenciosidade além de não ser representativa da população em geral. 


\section{Análise de resultados}

\subsection{Perfil da amostra}

A amostra foi composta totalmente por mulheres estudantes da PUC-Rio. A faixa etária das respondentes varia de 18 a 25 anos.

\subsection{Resultados do método 1}

O questionário online desenvolvido através do Qualtrics contou com uma amostra de 122 respondentes.

Como mencionado anteriormente, primeiramente o objetivo do questionário foi entender o comportamento do consumidor de produtos de beleza no geral. Como mostra o quadro 1 , podemos notar que a maior parte dos respondentes, correspondente a aproximadamente $87 \%$, tem o costume de comprar produtos de nas lojas físicas, o que se é esperado uma vez que ao comprar produtos de beleza espera-se um interação do clienteproduto, pelo menos na primeira vez de compra. Possivelmente, os respondentes que costumam fazer as compras online ou através de consultoras já compraram ao menos uma vez esse produto em uma loja física e/ou já utilizou o produto a ser comprado previamente.

Ainda assim, conforme o gráfico 1 , todos os respondentes, mesmo aqueles que não frequentam tanto as lojas, prezam mais pelo ambiente da loja em si (31\%), seguido pela exposição dos produtos (22\%) e a exposição dos preços cobrados $(20 \%)$, mostrando que as opções que envolvem os sentidos, nesse caso a visão, são os que mais influenciam na percepção do consumidor.

O restante foi avaliado como menos importante, sendo $17 \%$ a variedade dos produtos, $9 \%$ o espaço para circulação e $1 \%$ outras opções abertas que incluíram respostas como: a forma de tratamento com o cliente, a qualidade dos produtos, os produtos e os preços em si, e por fim, o cheiro do ambiente, o que chama a atenção para a questão sensorial que está sendo testada neste estudo. 
Quadro 1 - Onde os consumidores costumam comprar produtos de beleza

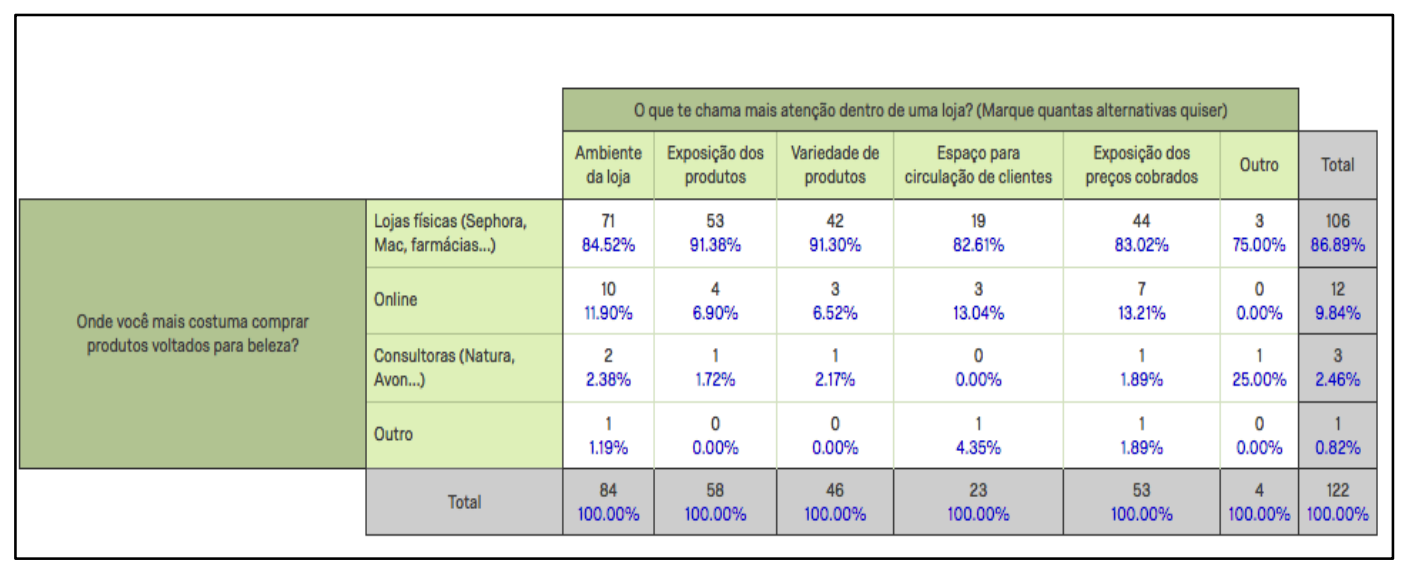

Fonte: Qualtrics/Pesquisa de Campo

Gráfico 1 - O que chama mais atenção dos respondentes dentro de uma loja

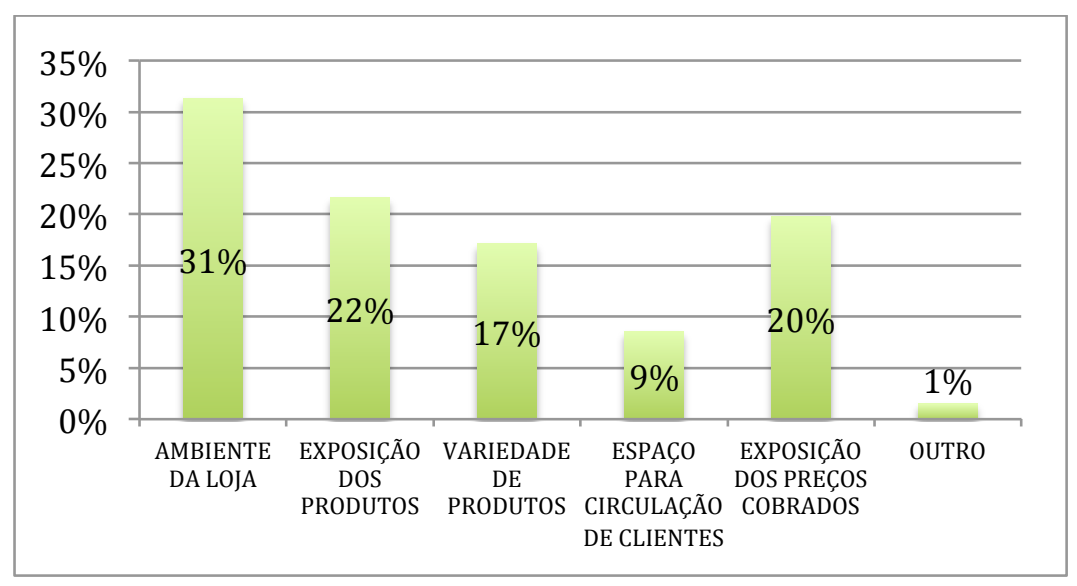

Fonte: Elaborado pela autora

Com o intuito de entender o que leva um consumidor a comprar um produto de beleza foram questionados os motivos, tendo como opções: por necessidade, vaidade, influência, para presentear alguém ou para aproveitar uma promoção. Nessa pergunta o respondente podia marcar mais de uma opção e foi identificado, como pode ser visto no gráfico 2, que o maior número de respostas foi por necessidade $(38,76 \%)$ e por vaidade $(32,54 \%)$, o que já era esperado uma vez que cosméticos estão sempre ligados a autoestima, embelezamento e cuidado com o corpo. 
Gráfico 2 - Motivo pelo qual o consumidor compra produtos de beleza

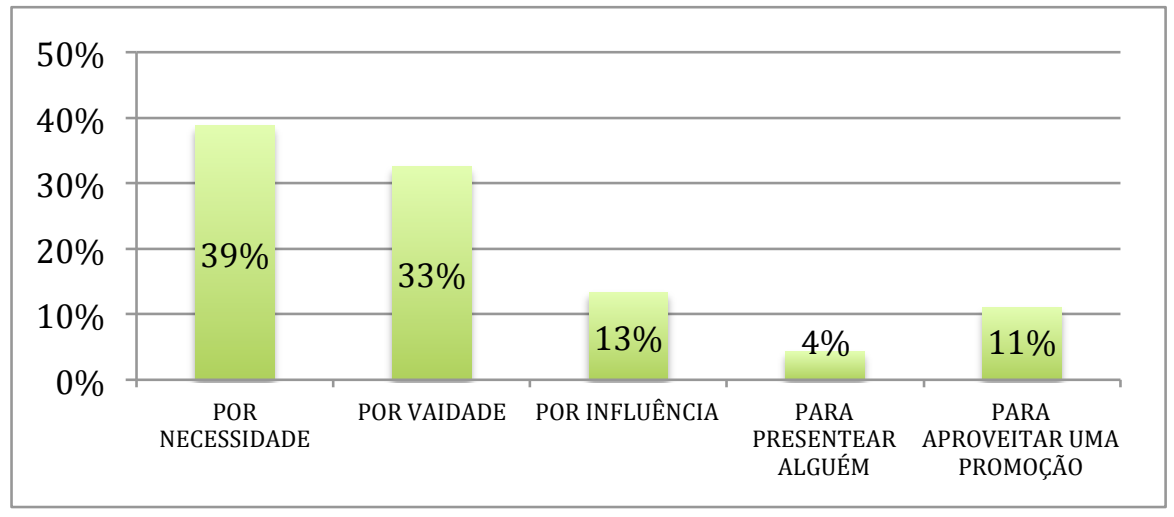

Fonte: Elaborado pela autora

Migrando para o lado sensorial da pesquisa, foi questionado se o respondente já deixou de comprar em alguma loja por algum motivo. Conforme o gráfico 3 , o maior índice de respostas ocorreu no mau atendimento $(27,44 \%)$ seguido pelo preço elevado atribuído aos produtos $(24,70 \%)$. Diante das opções sensoriais as a que mais parecem incomodar os clientes são o cheiro forte (10,98\%), seguido da música ambiente alta $(7,93 \%)$ e do mau cheiro $(7,01 \%)$, mostrando que o odor do ambiente é algo que realmente impacta na percepção do cliente sobre a loja, tanto positivamente quando negativamente. Já em relação à utilização dos 5 sentidos na hora de escolher uma maquiagem as respostas se restringiram, como era esperado, a somente 3 deles, sendo visão o maior, com 102 respostas, como pode ser visto no gráfico 4. É importante frisar que nessa questão não havia a opção de marcar mais de uma opção, o que significa que $9 \%$ das pessoas acreditam que o tato é o sentido mais importante ao se escolher um produto e $7 \%$ acreditam ser o olfato, o que é bem interessante uma vez que a visão é sempre o primeiro sentido a ter contato com o ambiente externo e, como mencionando anteriormente, a visão absorve mais informação que qualquer outro sentido (BLESSA, 2006).

Gráfico 3 - Motivo pelo qual o respondente já desistiu de comprar em uma loja de beleza

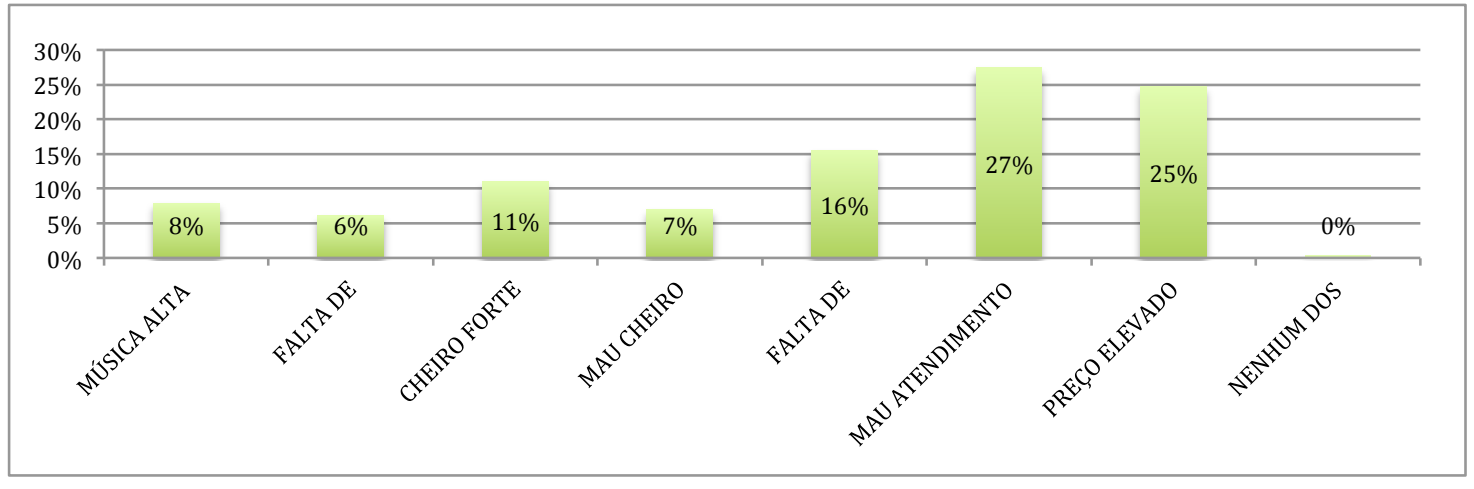

Fonte: Elaborado pela autora 
Gráfico 4 - Qual sentido acredita mais utilizar ao escolher um produto de beleza

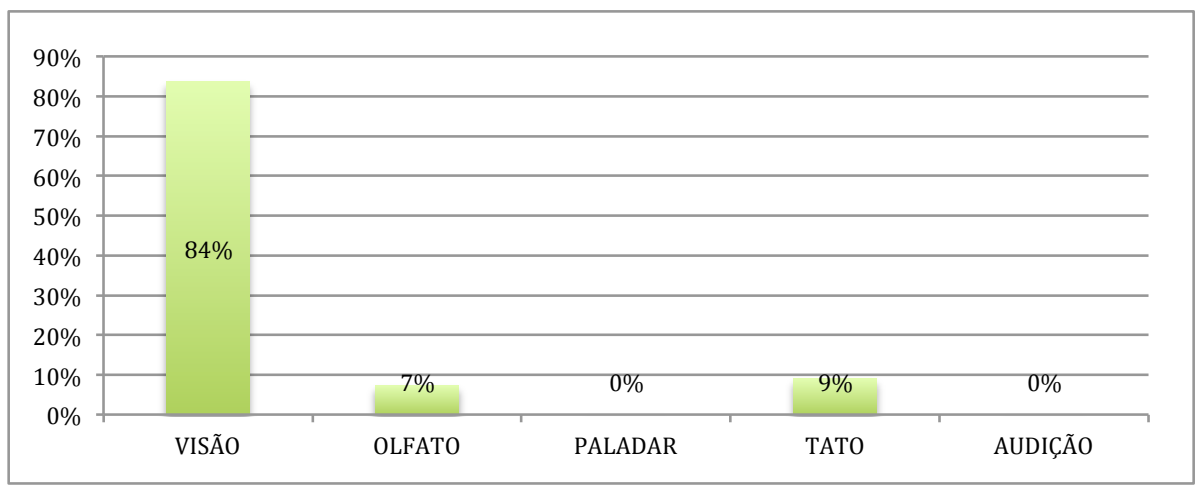

Fonte: Elaborado pela autora

Foi questionado também sobre a influência da música no comportamento do consumidor, onde como esperado, a maioria (48 pessoas) assume perceber influência dela no seu comportamento, podendo se sentir mais impulsivos ou não a comprar dependendo do que está tocando, conforme o gráfico 5 . Bem próximo a essa resposta, 45 pessoas acreditam que a música pode influenciar sim seu comportamento, mas não acreditam que seja o suficiente para mudar o seu comportamento de compra e o restante diz não perceber nenhuma influência. Ainda assim, devemos levar em conta que uma das questões do marketing sensorial é justamente influenciar o comportamento do consumidor sem que o mesmo perceba, o que leva a crer que os consumidores que afirmam não perceber influência podem ter sido impactados em algum momento mesmo que não tenham percebido.

Gráfico 5 - Influência da música sobre o comportamento de compra

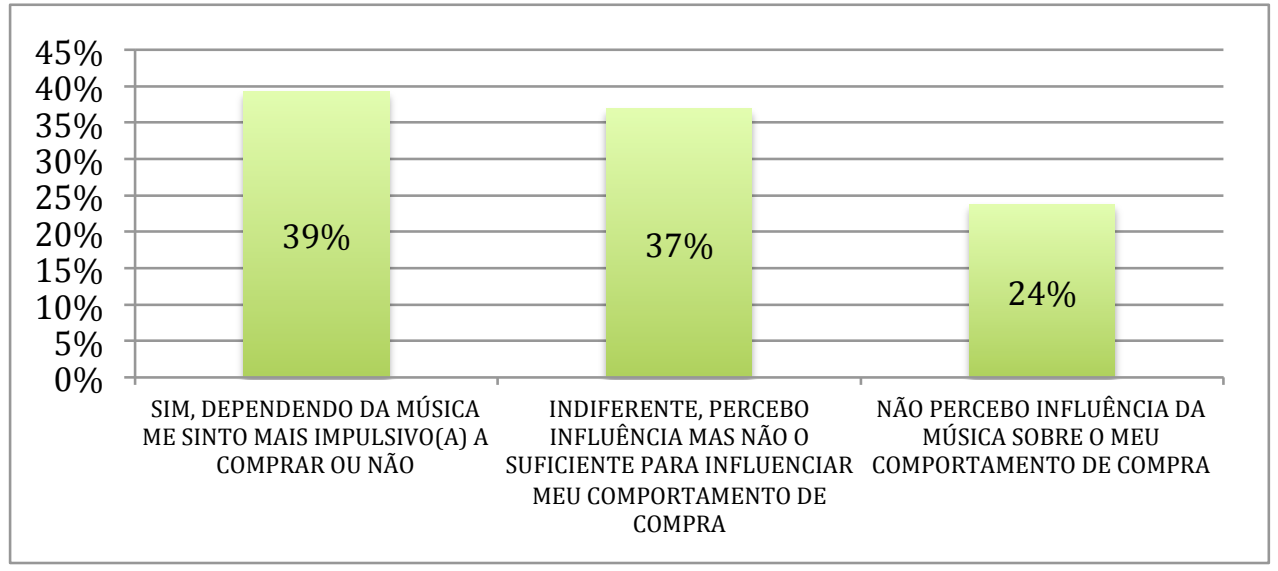

Fonte: Elaborado pela autora

Também é possível concluir, conforme mostra o gráfico 6, que a utilização de eventos com músicas e experimentações tem impacto sobre o consumidor de produtos de 
beleza. Metade dos respondentes acredita que esse tipo de experiência é necessária e desperta a curiosidade sobre o produto, além de um número alto de pessoas (35\%) que acredita que apesar de ser desnecessário, agrega valor ao produto.

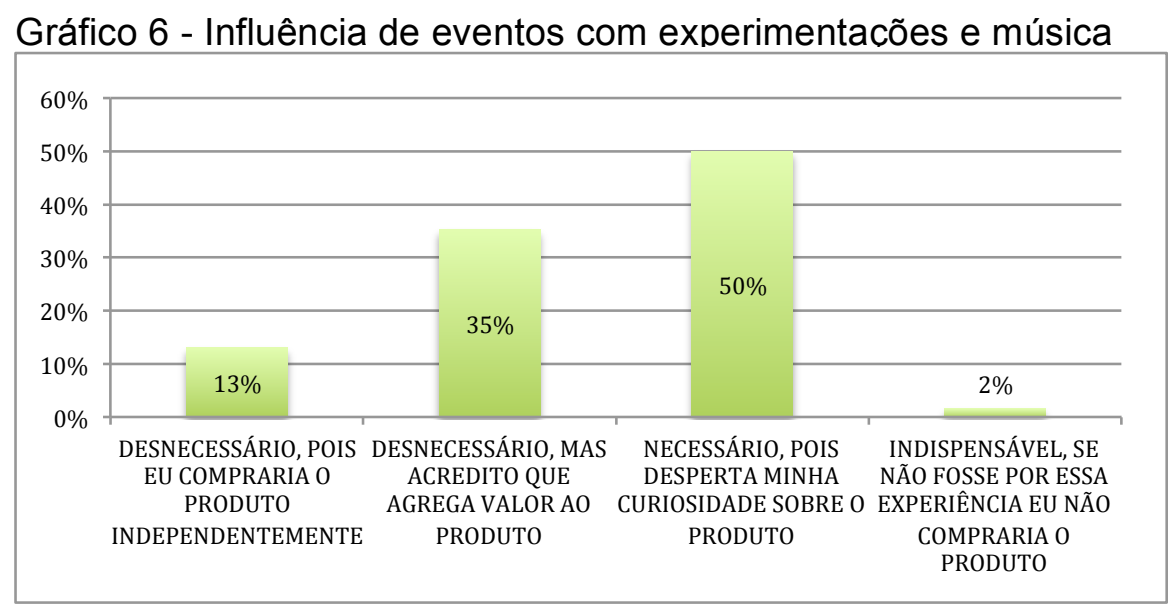

Fonte: Elaborado pela autora

Ainda sobre a importância da experimentação para os consumidores de produtos de beleza, com os resultados obtidos é possível perceber que é muito mais importante a experimentação de um perfume do que uma maquiagem antes de efetuar a compra. Ainda que isso possa ser esperado, uma vez que o odor é algo muito mais pessoal e que talvez não seja tão possível levar em consideração a opinião e indicação alheia, é interessante perceber que de fato nenhum dos 122 respondentes considerou fazer a compra de um perfume sem um provador disponível, conforme o gráfico 7 .

Já em relação a maquiagens, o número de pessoas que considera a experimentação antes da compra muito importante já é menor, provavelmente por ser um produto cuja indicação alheia às vezes por si só já é suficiente para influenciar na compra, visto no gráfico 8 .

Gráfico 7 - Importância de provar um perfume antes da compra

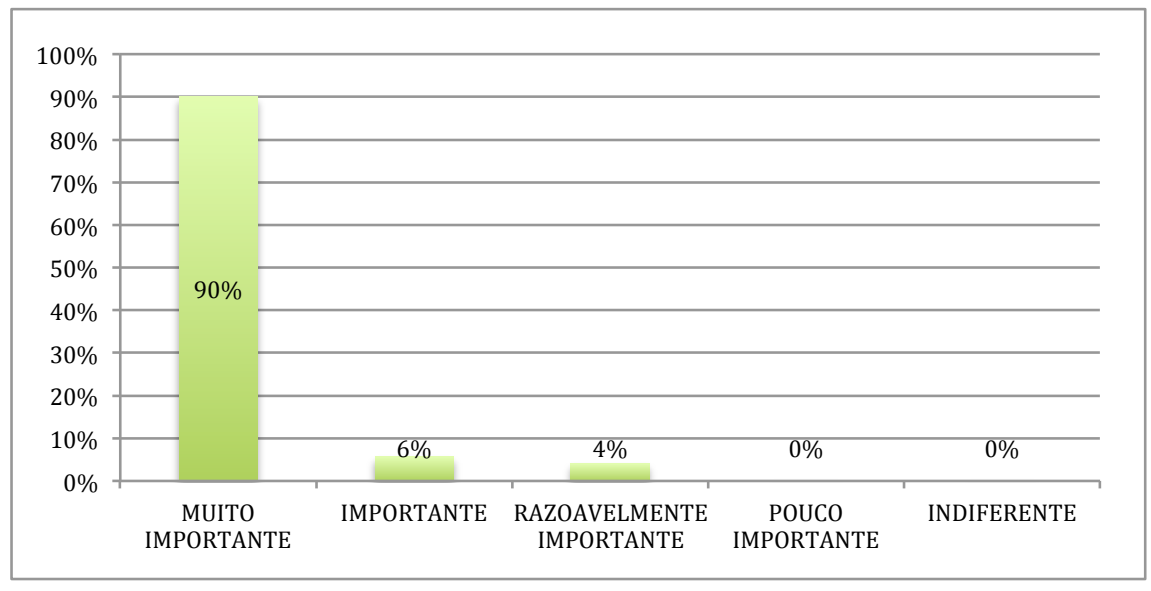

Fonte: Elaborado pela autora 
Gráfico 8 - Importância de provar uma maquiagem antes da compra

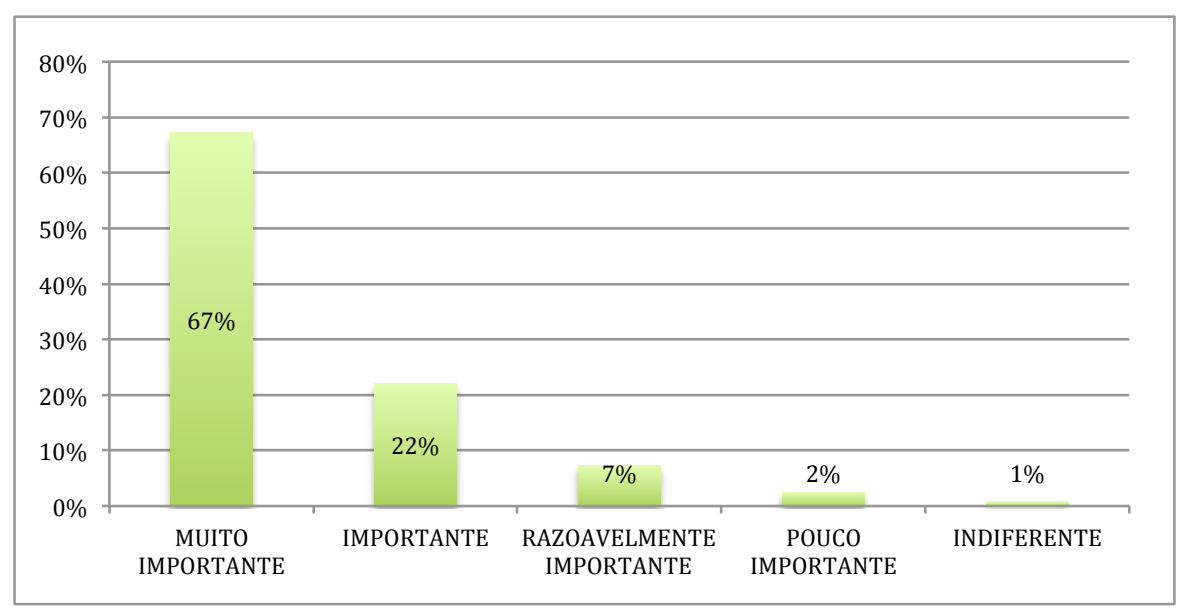

Fonte: Elaborado pela autora

Por fim, focando mais diretamente em produtos e o possível impacto sensorial, foram apresentados produtos existentes no mercado como exemplo. O pó bronzeador Délice de Poudre da Bourjois é um produto que contém aroma de chocolate e que foi utilizado como ponto de partida para entendimento da influência do odor. Nessa questão, era necessário responder se conhecia/já havia ouvido falar sobre o produto. Das 122 respostas, o gráfico 9 mostra que $52 \%$ não conheciam o produto, mas aqueles que respondiam que sim eram encaminhados para uma pergunta que questionava a influência do aroma de chocolate sobre o produto.

Como pode ser visto no gráfico $10,47 \%$ das pessoas acreditam que o cheiro não teve impacto direto na compra do produto, mas ainda assim acreditam que é um diferencial que as agrada. Em seguida, com 32\%, muitos dizem ser indiferentes ao aroma, enquanto outros (14\%) não gostam do cheiro e o restante $(7 \%)$ afirma ter comprado o produto justamente por causa do cheiro.

Isso mostra que ainda que a maioria que compre o produto não o leve conscientemente apenas pelo cheiro, o odor tem sim uma influência importante na sua escolha, agregando valor ao produto final. Além disso, existem aqueles que sofrem tanto com a influência do cheiro, que escolhem esse e possivelmente outros tipos de produto apenas pelo fato de ser aromatizado. 
Gráfico 9 - Quantidade de respondentes que conhecem o produto Délice de Poudre da Bourjois

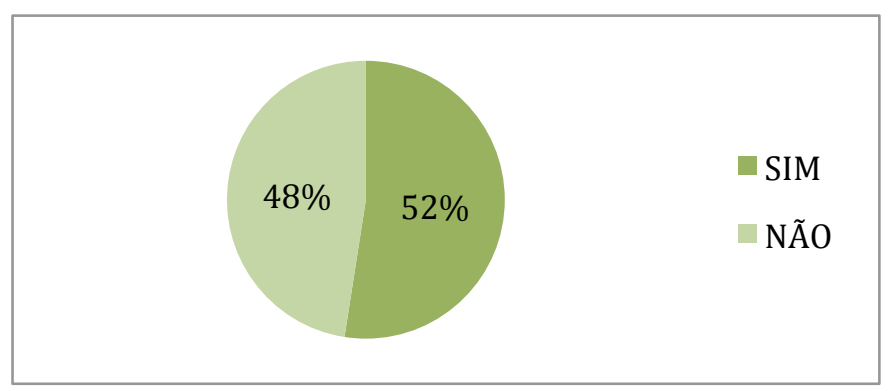

Fonte: Elaborado pela autora

Gráfico 10 - Influência do aroma do produto no momento de

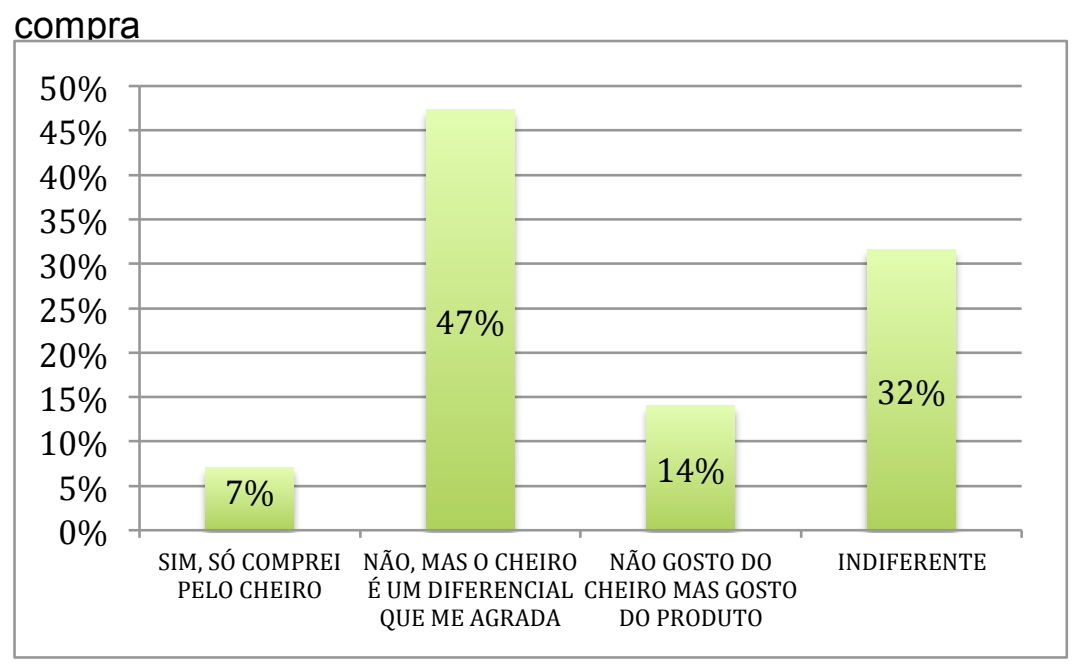

Fonte: Elaborado pela autora

Por fim, conforme explicado anteriormente, foi questionado a probabilidade de compra de dois produtos, no questionário desenvolvido online produtos mais "neutros", com o intuito de posterior comparação entre as respostas com o questionário presencial.

Em relação ao hidratante labial Nivea, as respostas ficaram mais restritas ao muito provável (18\%), provável (17\%) e boa possibilidade (16\%). Já em relação ao hidratante capilar L'Oreal Professionel, o maior índice de resposta se deu no muito provável $(17 \%)$, provável $(12 \%)$ e certamente ou praticamente certo (16\%), mostrando a boa aceitação pelos respondentes, conforme pode ser observado respectivamente nos gráficos 11 e 12 . 
Gráfico 11 - Probabilidade de compra da máscara de hidratação L'Oreal Professionel

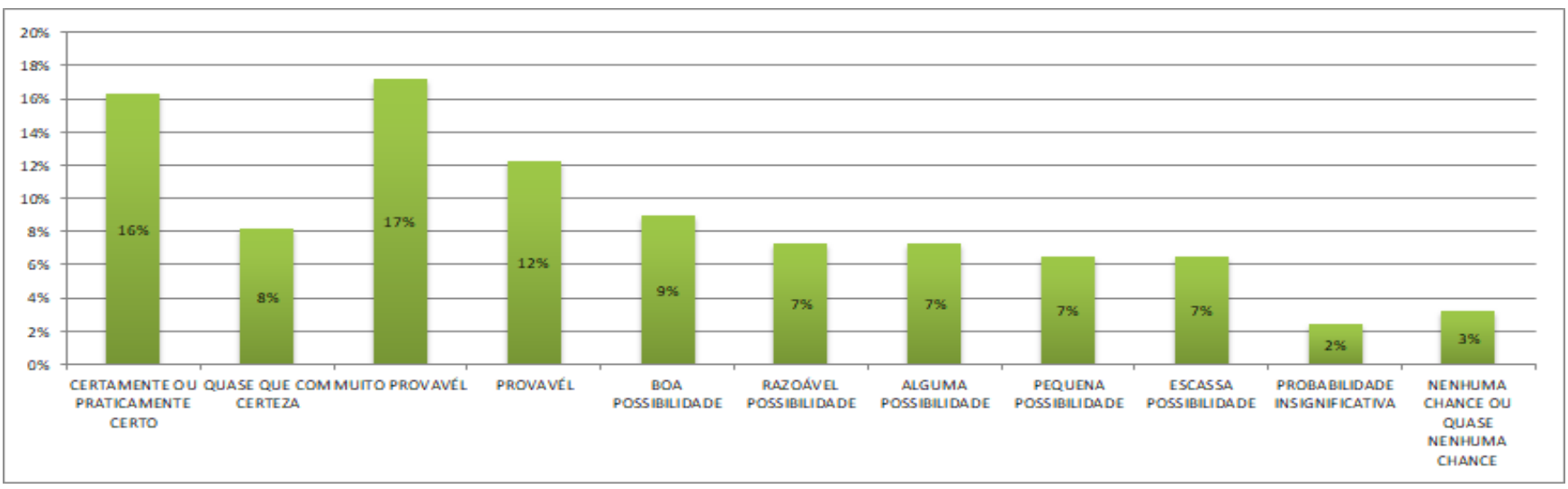

Fonte: Elaborado pela autora

Gráfico 12 - Probabilidade de compra do hidratante labial regular Nivea

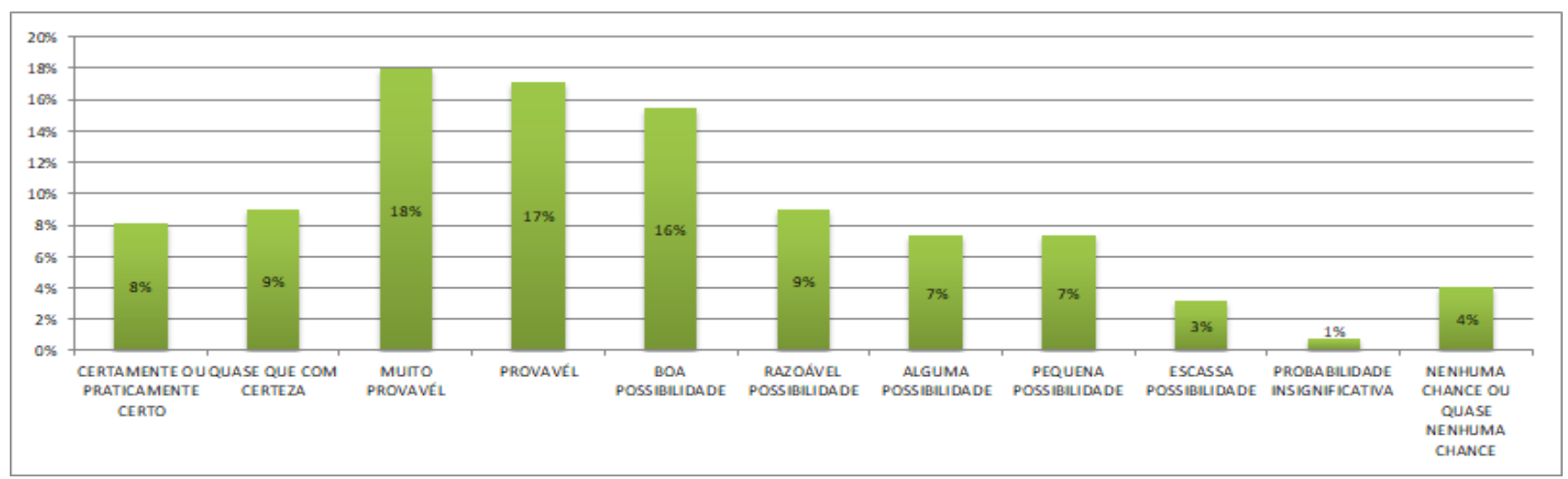

Fonte: Elaborado pela autora

\subsection{Resultados do método 2}

O questionário físico contou com 82 respostas que no geral foram bem parecidas com os as respostas do questionário online. Assim como no online, os respondentes confirmaram a suposição de que as compras de produtos de beleza são normalmente feitas em lojas físicas, provavelmente pela necessidade de sentir, tocar e experimentar o produto a ser comprado, aqui correspondendo a 83\% das respostas conforme gráfico 13 .

Além disso, o que mais chama a atenção dos respondentes dentro de uma loja de beleza continua sendo em primeiro lugar o ambiente da loja, seguido pela exposição dos produtos e a exposição dos preços cobrados, como pode ser visto no gráfico 14 , mais uma vez mostrando a importância das questões ligadas à visão diante da opinião e percepção do consumidor. A variedade dos produtos, ou seja, o sortimento mais amplo também tem certa 
importância, correspondendo a $19 \%$ das respostas, no entanto o espaço para circulação $(6 \%)$ e outras opções (4\%) não parecem ser tão importantes. Neste caso, as respostas abertas citaram o atendimento ao cliente e o preço dos produtos, ambos citados também no questionário online.

Gráfico 13 - Onde os consumidores costumam comprar produtos de beleza

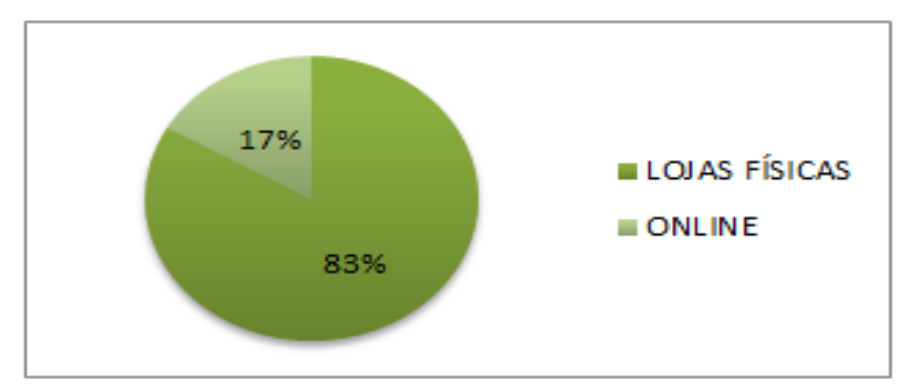

Fonte: Elaborado pela autora

Gráfico 14 - O que chama mais atenção dos respondentes dentro de uma

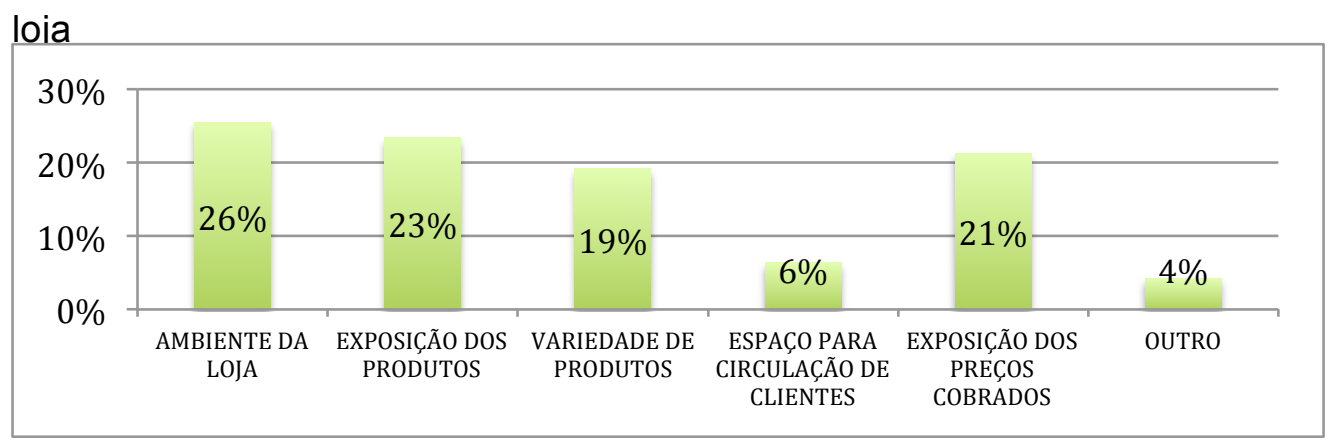

Fonte: Elaborado pela autora

Em relação ao motivo que leva à compra, como pode ser visto no gráfico 15 , mais uma vez a maior parte das respostas se deu por necessidade, aqui correspondendo a mais da metade dos respondentes, seguido da vaidade $(22 \%)$, influência (14\%), para aproveitar uma promoção (8\%) e para presentear alguém $(6 \%)$.

Primeiramente, as opções de necessidade e vaidade andam em conjunto, uma vez que um produto de beleza, muitas vezes, além de ajudar na melhoria de autoestima, também auxilia em diversos quesitos, o que explica a necessidade. Os consumidores que compram por influência, muito provavelmente, são aqueles que estão mais ligados nas redes sociais e na onda das blogueiras e youtubers que cada vez fazem mais reviews sobre produtos de beleza, influenciando diversas pessoas através das telas. Além disso, por maquiagens e derivados não serem produtos baratos, entende-se aqueles que os compram para aproveitar uma promoção ou até mesmo para presentear alguém. 
Gráfico 15 - Motivo pelo qual o consumidor compra produtos de beleza

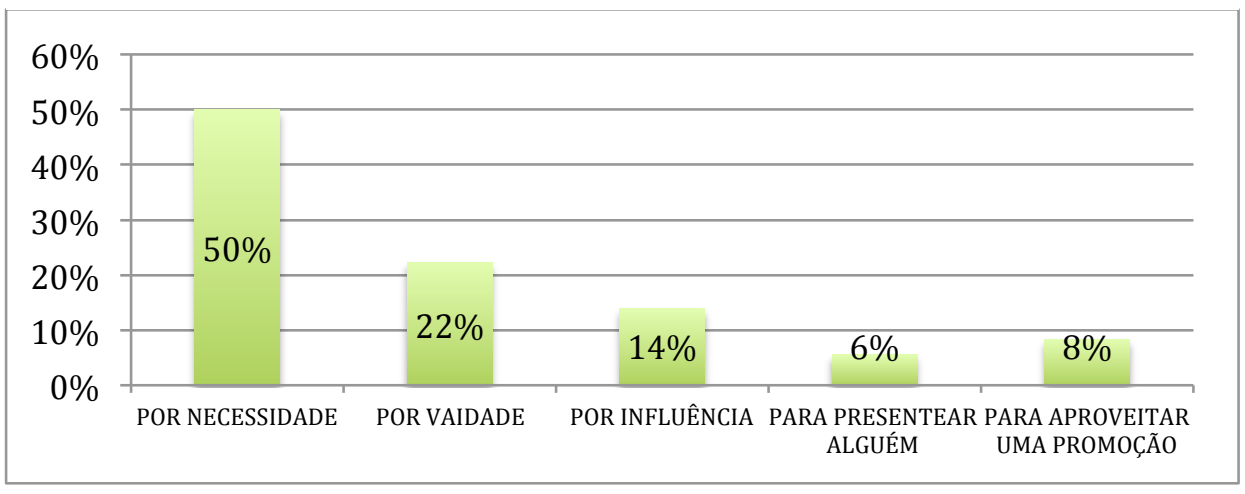

Fonte: Elaborado pela autora

Iniciando as análises das perguntas que tratam mais as questões sensoriais, nos motivos que impediram que o respondente fizesse ou finalizasse uma compra em alguma loja, a maior incidência de respostas se deu pela música alta (22\%), seguido do cheiro forte $(20 \%)$ e mau cheiro (17\%), como pode ser visto no gráfico 16 . O interessante é perceber que as três opções são ligadas a questões sensoriais, confirmando mais uma vez o impacto sobre o comportamento do consumidor.

Gráfico 16 - Motivo pelo qual o respondente já desistiu de comprar em uma loja de beleza

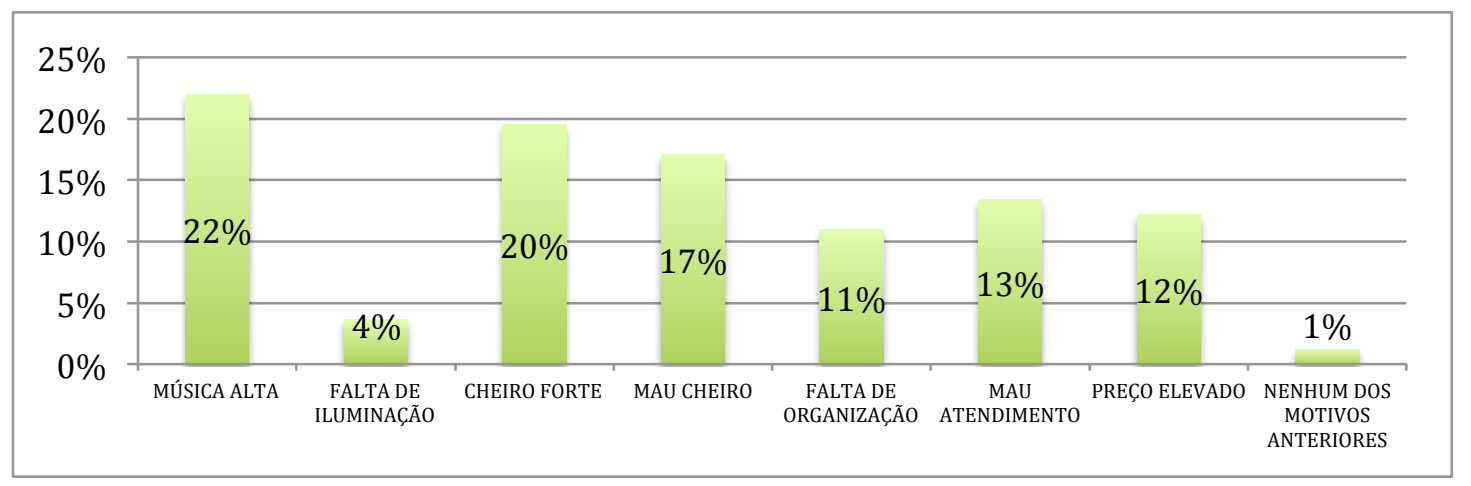

Fonte: Elaborado pela autora

Em relação à utilização dos sentidos no momento da compra, assim como no questionário online, as respostas se restringiram a respectivamente visão (59\%), olfato e tato, ambos com $19 \%$ das respostas, que pode ser visto no gráfico 17 . É interessante perceber que uma grande quantidade de pessoas priorizam o olfato e o tato frente à visão na escolha de um produto de beleza. Para essas pessoas, possivelmente a embalagem, relacionada à visão, não é a prioridade, mas sim a textura do produto no contato com o corpo e o cheiro dos mesmos. 
Gráfico 17 - Qual sentido acredita mais utilizar ao escolher um produto de beleza

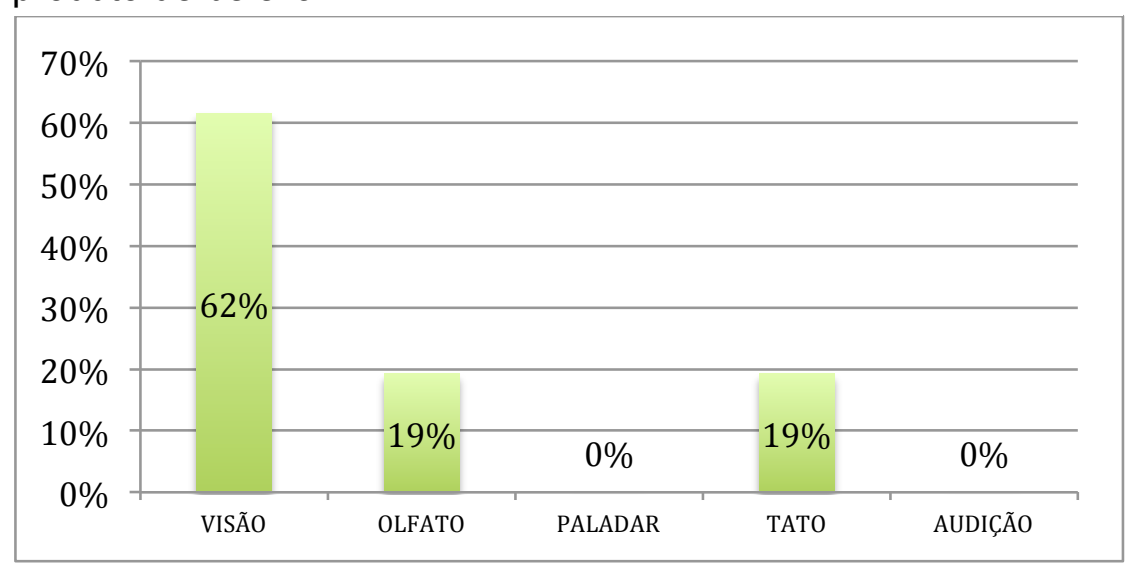

Fonte: Elaborado pela autora

Sobre a percepção da influência da música no processo de compra, como pode ser visto no gráfico 18 , mais uma vez a maior parte dos respondentes acreditam que ela tem influência no seu comportamento, o que está de acordo com as teorias do marketing que explicam como a música afeta diretamente os sentimentos e comportamento das pessoas.

Gráfico 18 - Influência da música sobre o comportamento de

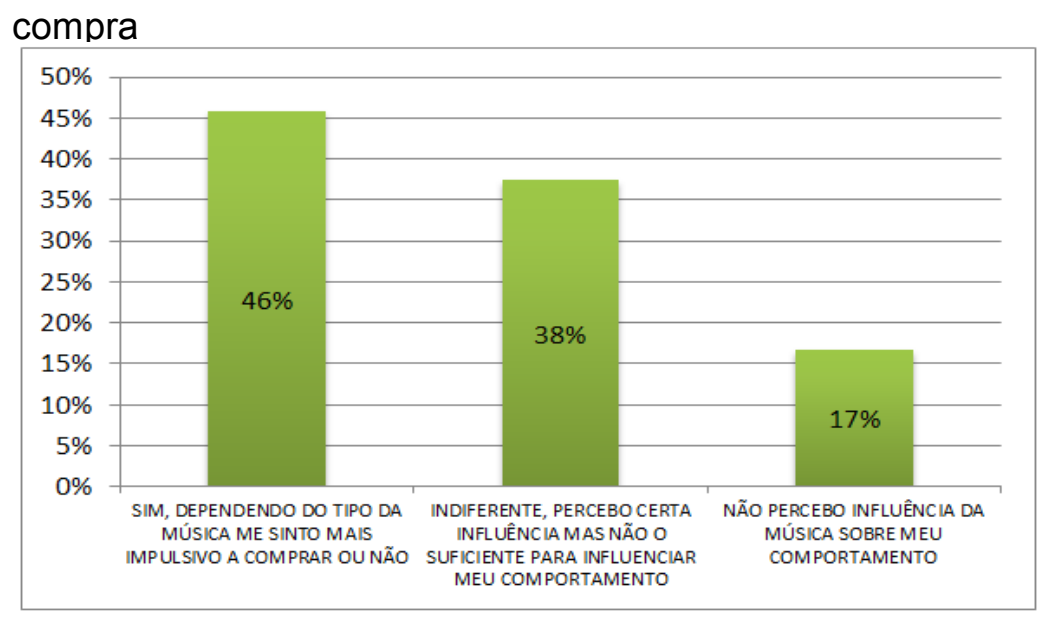

Fonte: Elaborado pela autora

Também é possível analisar a partir do gráfico 19 que a utilização de eventos com músicas e experimentações se fazem necessários uma vez que $70 \%$ dos respondentes acreditam que esses eventos deste tipo desperta a curiosidade no produto, levando eventualmente à compra. Interessante também perceber que a segunda opção com mais respostas $(17 \%)$ foi dos que acreditam que esse tipo de evento é indispensável, pois agrega tanto valor ao produto que se não fosse por isso nem os levariam. Isso confirma que o 
consumidor está cada vez mais interessado em ações que revolucionem a experiência de compra.

Gráfico 19 - Influência de eventos com experimentações e música

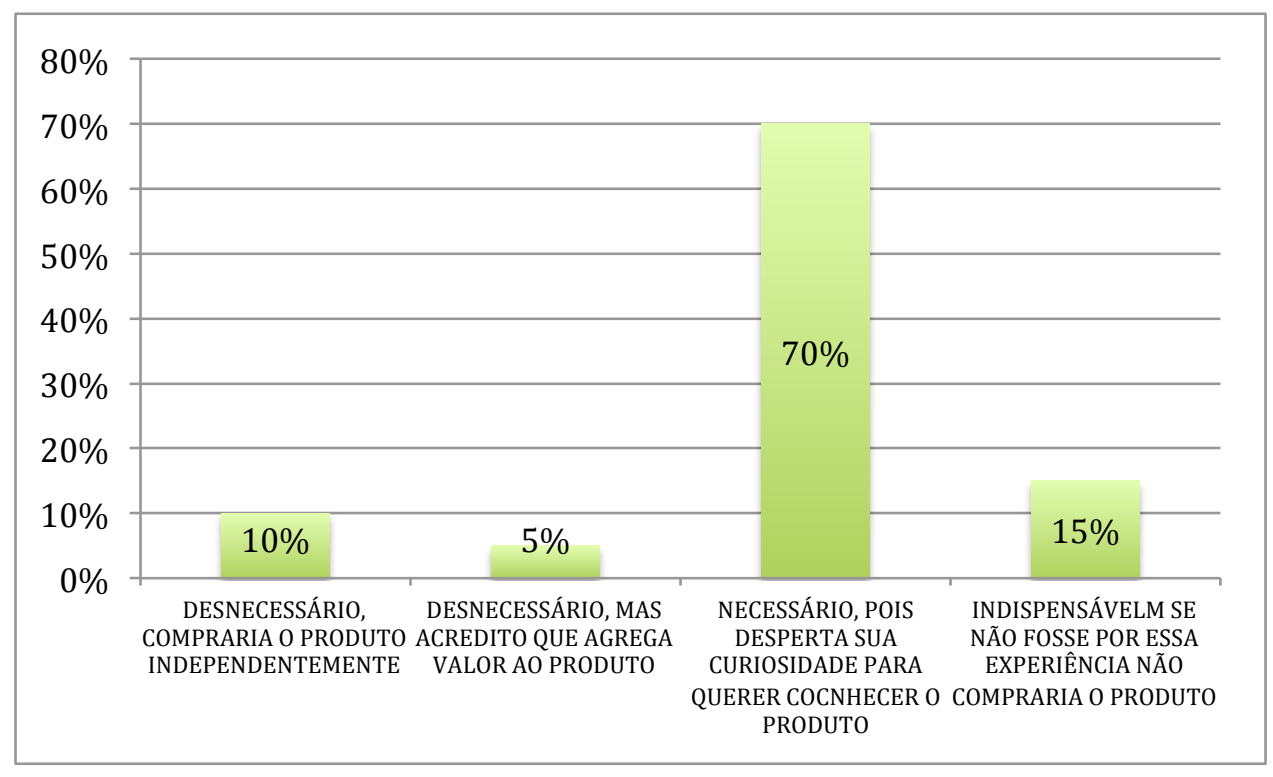

Fonte: Elaborado pela autora

Quanto à importância de provadores (testers) na hora da compra, assim como no questionário online e tanto para um perfume quanto para uma maquiagem, mais de $50 \%$ dos respondentes consideram ser muito importante, como pode ser visto nos gráficos 20 e 21 . Como dito anteriormente, o odor é algo considerado pela maioria algo extremamente pessoal e por isso a experimentação é algo quase que indispensável. Quanto às maquiagens, ainda que a compra possa estar sendo por influência ou baseada numa indicação, é algo que por costume se testa antes do momento da compra, o que as respostas confirmam.

Gráfico 20 - Importância de provar um perfume antes da compra

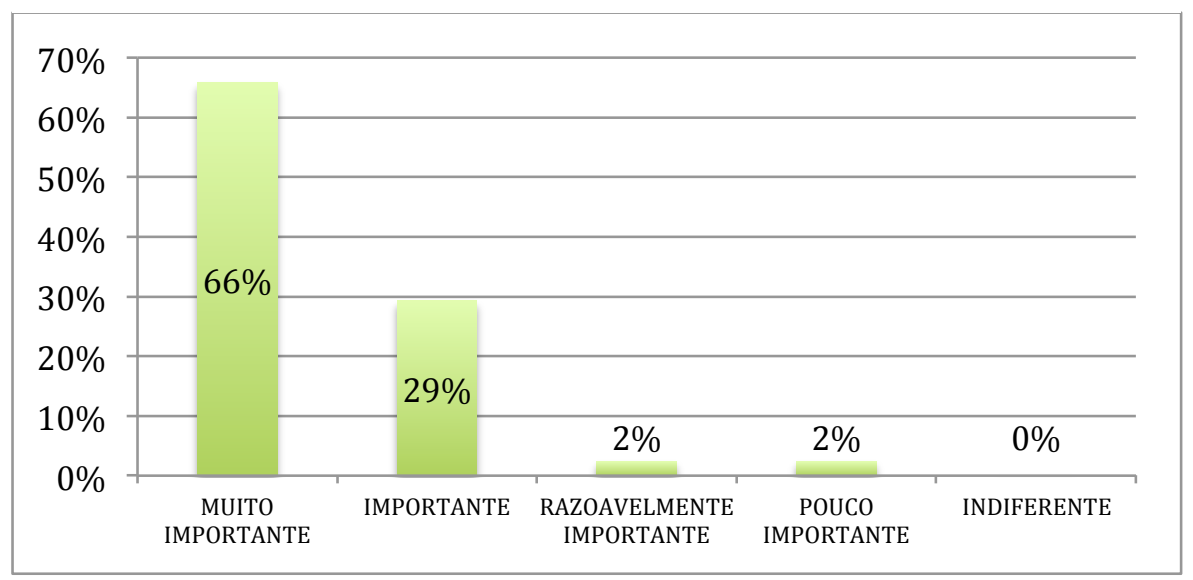

Fonte: Elaborado pela autora 
Gráfico 21 - Importância de provar uma maquiagem antes da compra

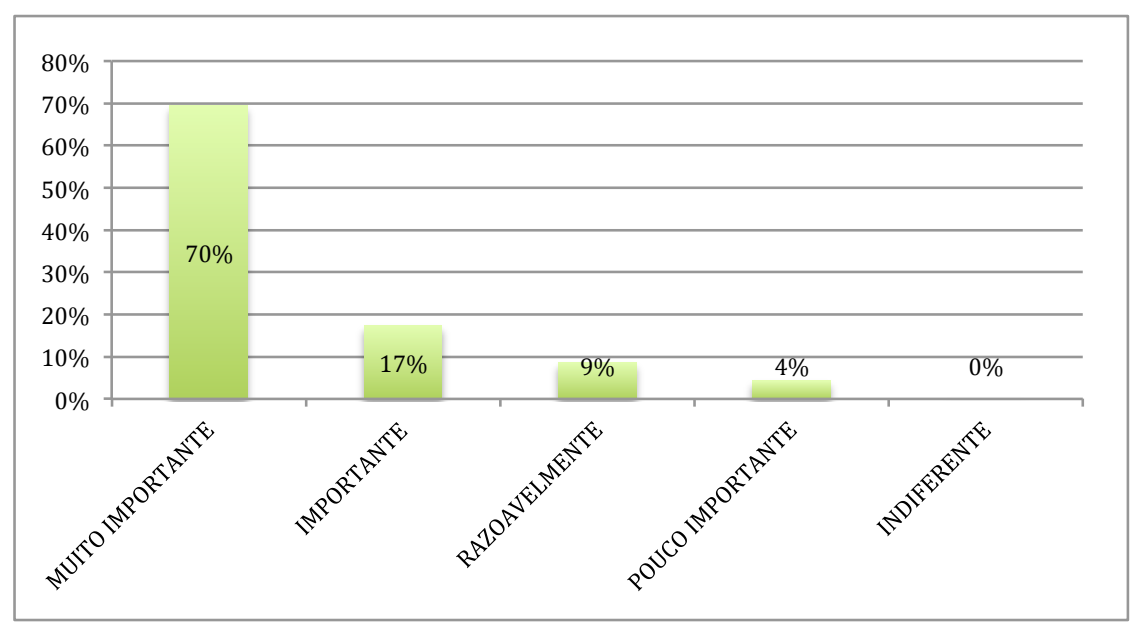

Fonte: Elaborado pela autora

Já quanto ao produto Délice de Poudre da Bourjois, conforme o gráfico 22, o número de pessoas do questionário físico que conhecem este produto foi menor que no questionário online, mas quase a metade dos respondentes (47\%) afirmou que o aroma de chocolate que ele possui é um diferencial que as agrada, apesar de não terem efetuado a compra só por isso. Através do gráfico 23 , é possível perceber que $37 \%$ delas afirmam ter comprado exclusivamente pelo cheiro, o que mais uma vez mostra a influência dos sentidos, nesse caso o olfato, sobre a escolha final do consumidor.

Gráfico 22 - Quantidade de respondentes que conhecem o produto Délice de Poudre da Bourjois

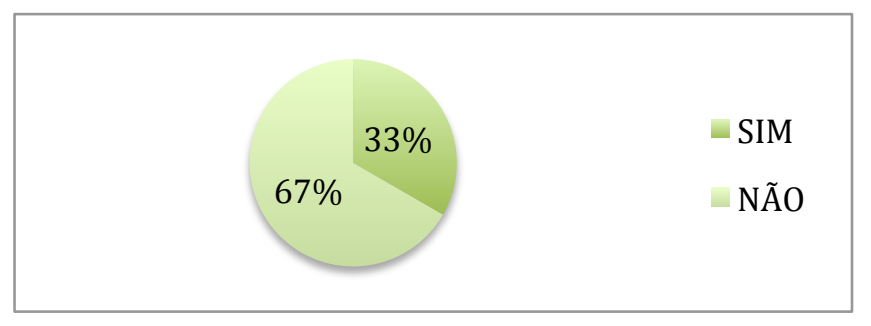

Fonte: Elaborado pela autora

Gráfico 23 - Influência do aroma do produto no momento de compra

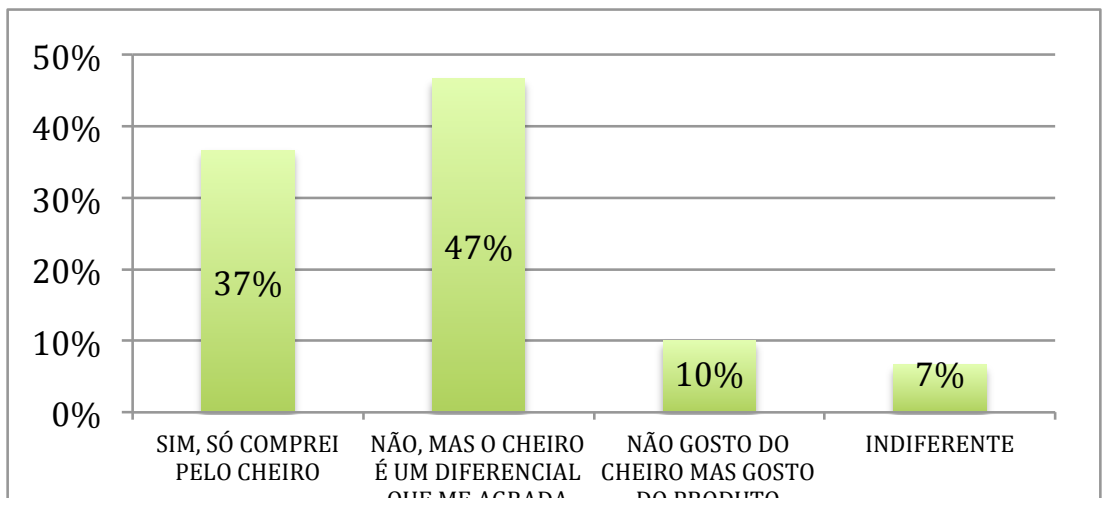


Por fim, foram feitas perguntas com o intuito de testar a probabilidade de compra de dois produtos, a única diferença entre o questionário online e o físico. Neste, foi apresentado primeiramente o hidratante labial Nivea com sabor e odor de morango, seguido de uma máscara de hidratação da Lola Cosmetics. Também foi utilizado um aroma de morango nas folhas de papel onde o questionário era apresentado com o intuito de entender se o cheiro influenciaria nas respostas.

Conforme pode ser visto nos gráficos 24 e 25, em ambos os casos as respostas foram positivas, estando sempre com mais de $80 \%$ entre as opções positivas de intenção de compra (certamente ou praticamente certo, quase que com certeza, muito provável, provável e boa possibilidade).

Gráfico 24 - Probabilidade de compra do hidratante labial de morango Nivea

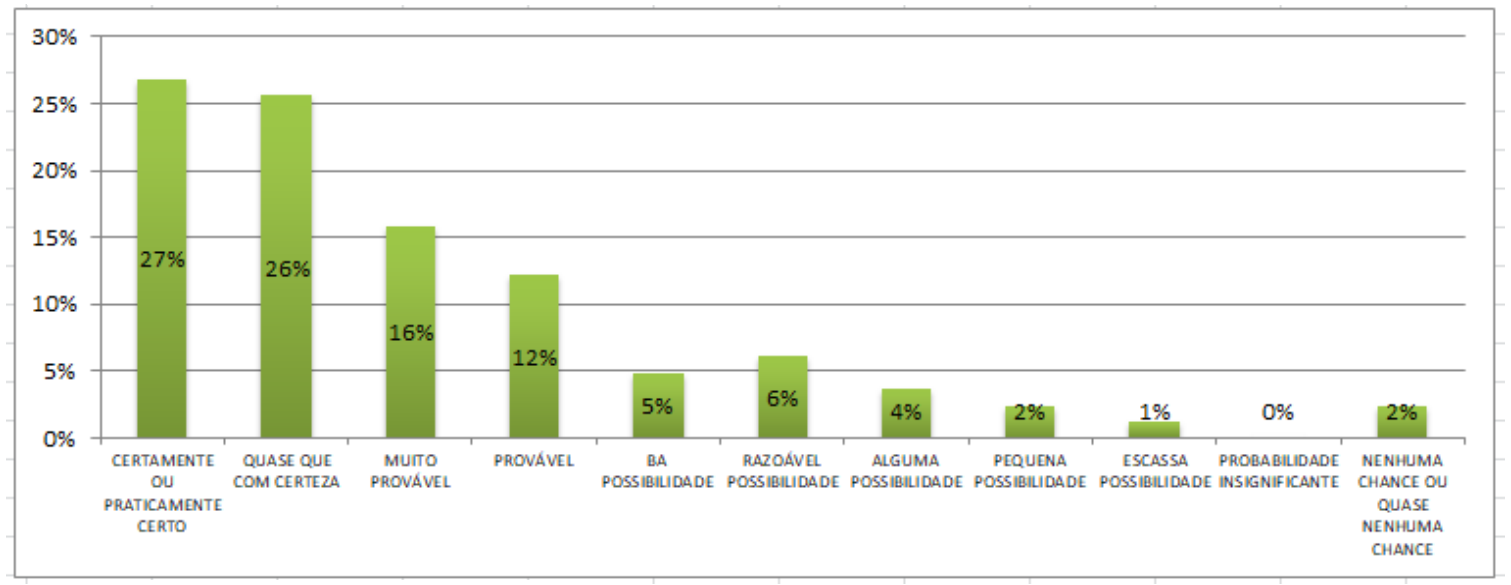

Fonte: Elaborado pela autora

Gráfico 25 - Probabilidade de compra da máscara de hidratação Lola Cosmetics

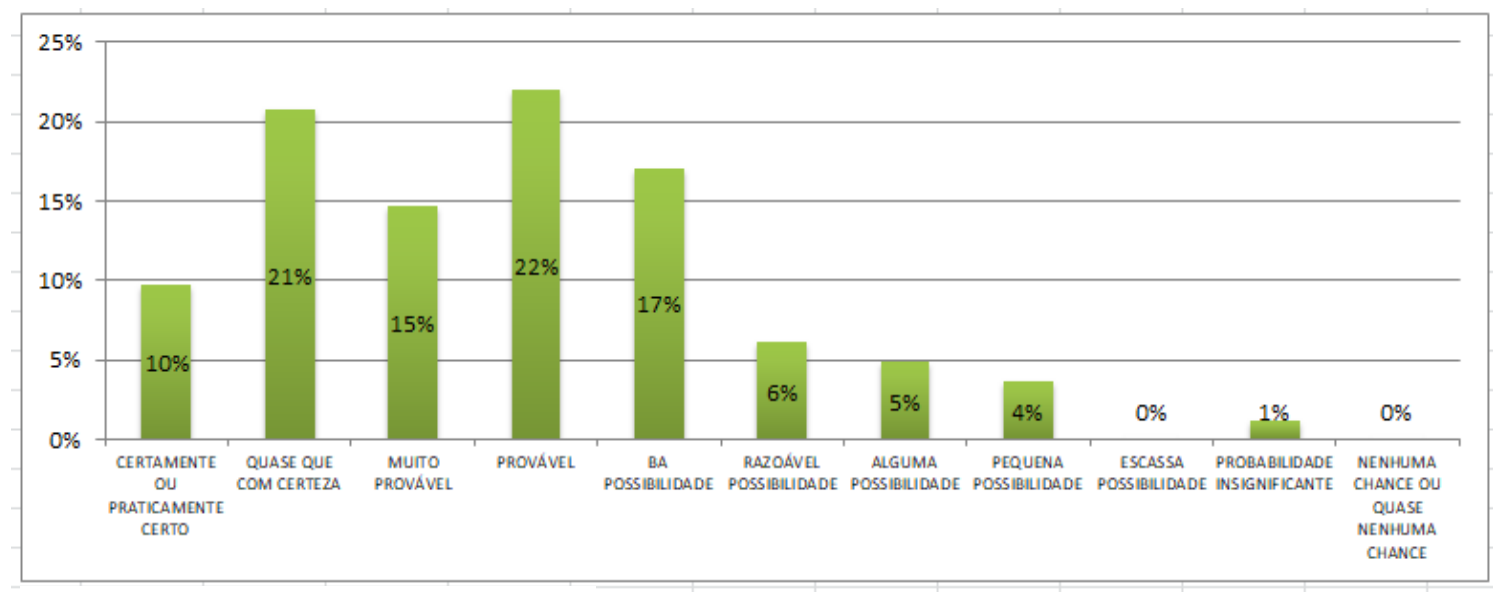

Fonte: Elaborado pela autora 
No caso do hidratante labial com cheiro de morango, a maior parte das respostas ficou dividida entre "certamente ou praticamente certo" (28\%) e "quase que com certeza" (27\%). Isso mostra a grande aceitação do produto pelo público e leva a conclusão de que o odor de morango na folha pode ter tido um papel essencial nessas respostas, uma vez que no questionário online além das respostas terem sido muito mais distribuídas entre as 11 opções, o maior índice ficou com "muito provável", com apenas $18 \%$ das respostas.

Já em relação ao creme capilar, o maior índice de respostas se deu no "provável" com $22 \%$ das respostas. Ainda que com o creme de hidratação da L'Oreal Professionel o maior índice de respostas tenha sido muito provável (17\%), na consolidação das respostas percebe-se que $84 \%$ das respostas no questionário físico foram positivas, frente a apenas $62 \%$ do questionário online.

Nesse caso, conclui-se que uma possível explicação é a influência do impacto visual entre os dois produtos, já que ambos possuem a mesma função, além da L'Oreal ser uma marca muito mais consolidada no mercado do que a Lola Cosmetics. No caso da Lola, a embalagem do produto era muito mais elaborada e autoexplicativa, o que pode ter funcionado como peça chave de atração do consumidor. 


\section{Conclusão}

Esse trabalho pretendeu investigar a influência da utilização do marketing sensorial em lojas e produtos de beleza sobre o comportamento de consumidores do Rio de Janeiro. $O$ foco do estudo se restringiu a três dos cinco sentidos, sendo eles: visão, audição e olfato.

Para aprofundar a análise pretendida, investigou-se a perspectiva de diversos autores sobre conceitos relacionados ao tema como, por exemplo, comportamento do consumidor, atmosfera e imagem da loja e a definição de marketing sensorial. Para entender a influência, foi realizada uma pesquisa quantitativa com dois questionários que se diferenciavam pelo método de aplicação e pelas imagens utilizadas, além de haver uma essência de morango nas folhas de papel de um deles.

Através dos resultados obtidos foi possível concluir que a utilização de estímulos sensoriais, tanto no ponto de venda quanto nos produtos, surte efeitos no processo de compra e escolha do consumidor, ainda que muitas vezes os mesmos não percebam.

Como se era esperado, a visão é sempre o primeiro sentido que o cliente utiliza como medidor no processo de compra. A apresentação, tanto do ambiente quanto do produto, são essenciais na hora do processo de compra em uma loja ou de um produto de beleza.

Em relação à audição, foi possível concluir que a música no ambiente da loja surte tanto efeito que é capaz de estimular ou até desestimular uma venda. Um som ambiente muito alto, por exemplo, se apresentou como um grande problema para diversos respondentes dos questionários.

Por fim, os estímulos olfativos também se apresentaram como capazes de influenciar o comportamento do consumidor de produtos de beleza. O questionário que apresentava folhas com essência de morango, por exemplo, recebeu mais respostas positivas em relação à compra de um produto que continha essência do que no questionário online, o que mostra que, mesmo que inconscientemente, o odor na folha pode ter influenciado na escolha da resposta.

Dessa forma, conclui-se que a utilização dos estímulos sensoriais tanto no ambiente de loja quanto nos produtos são capazes de impactar o comportamento e consequentemente o processo de compra do consumidor, que já não se satisfaz mais com apenas bons produtos na vitrine. 


\subsection{Aplicações gerenciais}

A partir da análise do presente estudo é possível identificar algumas práticas de marketing sensorial que podem ser aplicadas, tanto nos produtos quanto em ambientes de venda.

Em relação aos produtos, a utilização de embalagens mais elaboradas torna-se essencial uma vez que foi possível concluir que a mesma tem grande influência sobre a escolha de compra do consumidor, que quando se depara com dois produtos semelhantes tende a preferir aquele que tem uma embalagem mais divertida e auto explicativa, independente da marca.

Já em relação ao ponto de venda, é necessário um olhar atento principalmente aos aspectos sensoriais ligados à audição e olfato. É importante que o som do ambiente esteja de acordo com o público que pretende agradar, ou seja, músicas mais animadas onde o público alvo são pessoas mais jovens, por exemplo. Além disso, também é necessário atenção ao cheiro do ambiente, que quando muito forte costuma incomodar o cliente. 


\section{Referências Bibliográficas}

ABIHPEC. Mercado brasileiro de HPPC: quarta posição mundial com sensação de terceira. Disponível em: <https://abihpec.org.br/2017/02/mercado-brasileiro-de-hppc-quartaposicao-mundial-com-sensacao-de-terceira/>. Acesso em: 16 jun. 2018.

ACTIVTSENS. Sephora, la séduction par les sens. activtsens. Disponível em: <https://activtsens.wordpress.com/2015/03/22/sephora-la-seduction-par-les-sens/>. Acesso em: 1 set. 2018.

ALMEIDA, HAMILTON. Perspectivas 2017 - Cosméticos: Inovação e diversificação de produtos estimulam vendas no país e também no exterior. QUÍMICA - O Portal da Química Brasileira e da Revista Química e Derivados. Disponível em: $<$ https://www.quimica.com.br/perspectivas-2017-cosmeticos-inovacao-e-diversificacao-deprodutos-estimulam-vendas-no-pais-e-tambem-no-exterior/2/>. Acesso em: 15 jun. 2018.

BLESSA, R. Merchandising no ponto-de-venda. 4.ed. São Paulo: Atlas, 2006.

BORDIEU, P. A distinção - Crítica Social do Julgamento. 2. ed. São Paulo: Editora Zouk, 2007.

BRAZIL BEAUTY NEWS. Sephora: Expansão da nova geração de lojas conectadas. Disponível em: <http://www.brazilbeautynews.com/sephora-expansao-da-nova-geracao-delojas,2343>. Acesso em: 13 jun. 2018.

CAMARGO, Heloiza. Uso Correto do marketing sensorial pode ajudar a vender mais. Disponível em: http://revistapegn.globo.com/Revista/Common/0,,EMI137208-17200,00USO+CORRETO+DO+MARKETING+SENSORIAL+PODE+AJUDAR+A+VENDER+MAIS.ht ml. Acesso em 13 jun. 2018

CHURCHILL, Gilbert A.; PETER, J. Paul. Marketing: criando valor para os clientes. Tradução da 2a. ed. São Paulo: Saraiva, 2005

GIL, A. C. Métodos e técnicas de pesquisa social. São Paulo: Atlas, 1999. 
FILER, Marc. Le Marketing Sensoriel: La Quête de L` Intégration Théorique et Managériale. 2003.

KOTLER, P.; KELLER, K. Administração de Marketing. São Paulo: Prentice Hall, 2009.

L'ORÉAL. L'Oréal 2016: Cosmetics Market - Annual report. Disponível em: <https://www.loreal-finance.com/en/annual-report-2016/cosmetics-market>. Acesso em: 25 set. 2018.

L'ORÉAL. L'Oréal 2017: Cosmetics Market - Annual report. Disponível em: <https://www.loreal-finance.com/en/annual-report-2017/cosmetics-market>. Acesso em: 15 set. 2018.

LVMH. Sephora named Retailer of the Year - LVMH. Disponível em: <https://www.Ivmh.com/news-documents/news/sephora-named-retailer-of-the-year/>. Acesso em: 24 jun. 2018.

MALHOTRA, Naresh K., ROCHA, Ismael.; LAUDISIO, Maria Cecilia.; ALTHEMAN, Édman.; BORGES, Fabio Mariano. Introdução à Pesquisa de Marketing. 1a. ed. São Paulo: Pearson, 2006.

TEIXEIRA, Anne K.G., BARBOSA, Maria de L.A. O Sistema de Oferta de Restaurantes de Alta Gastronomia: Uma Perspectiva Sensorial das Experiências de Consumo. Rio de Janeiro-RJ; set 2008.

ORBIS. Global Cosmetics Products Market-Analysis of Growth, Trends and Forecasts (2018-2023). Disponível em: <http://orbisresearch.com/reports/index/global-cosmeticsproducts-market-analysis-of-growth-trends-and-forecasts-2018-2023>. Acesso em: 3 out. 2018.

PAIVA, Sandra. A Embalagem Como Forma de Comunicação e Expressão. Brasil Escola. Disponível em <https://monografias.brasilescola.uol.com.br/arte-cultura/aembalagem-como-forma-comunicacao-expressao.htm>. Acesso em 1 set. 2018.

PANORAMA FARMACÊUTICO. Natura volta a liderar mercado cosmético no país. Panorama Farmacêutico. Disponível em: 
<https://panoramafarmaceutico.com.br/2018/04/18/natura-volta-a-liderar-mercadocosmetico-no-pais-aponta-euromonitor/>. Acesso em: 1 set. 2018.

PETER, J. Paul; OLSON, Jerry C. Comportamento do consumidor e estratégia de marketing. 14. ed. São Paulo: Pearson, 2013.

RETAIL DIVE. Store Concept of the Year: Sephora. Retail. Disponível em: < https://www.retaildive.com/news/store-concept-of-the-year->. Acesso em: 1 set. 2018.

REUTERS. Global Cosmetics Products Market expected to reach USD 805.61 billion by 2023 - Reuters. Disponível em: <https://www.reuters.com/brandfeatures/venturecapital/article?id=30351>. Acesso em: 25 set. 2018.

SEBRAE MERCADOS. Mercado de Cosméticos - SEBRAE MERCADOS. Disponível em: <http://www.sebraemercados.com.br/mercado-de-cosmeticos/>. Acesso em: 20 set. 2018.

SBIE. Entenda o conceito de Marketing Sensorial e como pode ser trabalhado junto às emoções. Disponível em: <http://www.sbie.com.br/blog/entenda-o-conceito-de-marketingsensorial-e-como-pode-ser-trabalhado-junto-as-emocoes/>. Acesso em: 15 jun. 2018.

SOLOMON, M. O comportamento do consumidor. Porto Alegre: Bookman, 2016.

SOUZA, Maiara. Natura é lider no setor de beleza no Brasil. Disponível em: $<$ https://franquia.com.br/noticias/natura-e-lider-no-setor-de-beleza-no-brasil/>. Acesso em: 1 set. 2018.

TERRA, Thiago. Comportamento do consumidor dita mudanças no varejo. Mundo do Marketing. Disponível em: <https://www.mundodomarketing.com.br/reportagens/pdv/4439/comportamento-doconsumidor-dita-mudancas-no-varejo.html>. Acesso em: 15 jun. 2018.

ZIKMUND, William G. Princípios da pesquisa de marketing. 2a. ed. São Paulo: Thomson, 2006. 


\section{Anexo 1 - Questionário presencial}

1. O que te chama mais atenção dentro de uma loja especializada em produtos de beleza? (Marque quantas alternativas quiser)
a. Ambiente da loja
b. Exposição dos produtos
c. Variedade de produtos
d. Espaço para circulação de clientes
e. Exposição dos preços cobrados
f. Outro:

2. Onde você costuma comprar produtos voltados para beleza?

a. Lojas físicas (Sephora, MAC, Farmácias..)

b. Online

3. Complete a frase: costumo comprar produtos de beleza: (marque quantas alternativas quiser)
a. Por necessidade
b. Por vaidade
c. Por influência
d. Para presentear alguém
e. Para aproveitar uma promoção

4. O que você leva em conta na hora de escolher uma maquiagem? (numerar por ordem de importância)

Preço
Embalagem
Marca
Indicação
Custo benefício


5. Complete a frase: costumo entrar em lojas especializadas em beleza (ex: SEPHORA, The Beauty Box, MAC, Clinique, O Boticário): (marque quantas alternativas quiser)
a. Quando preciso comprar produtos
b. Para experimentar produtos
c. Para descobrir checar os lançamentos
d. Pelos serviços oferecidos (cursos de maquiagem, serviços de sobrancelha etc)
e. Pela ambiente

6. Você já deixou de comprar em alguma loja por alguns dos motivos abaixo?
a. Música alta
b. Falta de iluminação
c. Cheiro forte
d. Mau cheiro
e. Falta de organização
f. Mau atendimento
g. Preço elevado
h. Nenhum dos motivos anteriores

7. Em relação aos 5 sentidos qual você acredita mais usar na hora de escolher uma maquiagem?
a. Visão
b. Olfato
c. Paladar
d. Tato
e. Audição

8. Você acredita que o tipo de música tocado na loja influencia no seu comportamento de compra?

a. Sim, dependendo do tipo da música me sinto mais impulsivo a comprar ou não.

b. Indiferente, percebo certa influência mas não o suficiente para influenciar meu comportamento

c. Não percebo influência da musica sobre meu comportamento

9. Na sua opinião, a utilização de eventos com música e degustações como forma de lançar e promover um produto é:

a. Desnecessário, compraria o produto independentemente 
b. Desnecessário, mas acredito que agrega valor ao produto

c. Necessário, pois desperta sua curiosidade para querer conhecer o produto

d. Indispensável, se não fosse por essa experiência não compraria o produto

10. Uma loja está promovendo uma experimentação de um produto, o qual você não pensava em comprar mas é levado a experimentar e gosta bastante. Qual a probabilidade de comprar esse produto?
a. Certamente ou praticamente certo
b. Quase que com certeza
C. Muito provável
d. Provável
e. Boa possibilidade
f. Razoável possibilidade
g. Alguma possibilidade
h. Pequena possibilidade
i. Escassa possibilidade
j. Probabilidade insignificante

k. Nenhuma chance ou quase nenhuma chance

11. Você entra em uma loja para comprar um produto que precisa, qual a probabilidade de acabar sendo influenciada e levar mais alguma outra coisa?
a. Certamente ou praticamente certo
b. Quase que com certeza
C. Muito provável
d. Provável
e. Boa possibilidade
f. Razoável possibilidade
g. Alguma possibilidade
h. Pequena possibilidade
i. Escassa possibilidade
j. Probabilidade insignificante
k. Nenhuma chance ou quase nenhuma chance

12. Qual a importância de um perfume ter um provador (tester) na hora da compra?
a. Muito importante
b. Importante
c. Razoavelmente importante 

d. Pouco importante
e. Indiferente

13. Qual a importância de uma maquiagem ter um provador (tester) na hora da compra?
a. Muito importante
b. Importante
c. Razoavelmente importante
d. Pouco importante
e. Indiferente

14. Você já utilizou ou já ouvir falar do produto da foto?
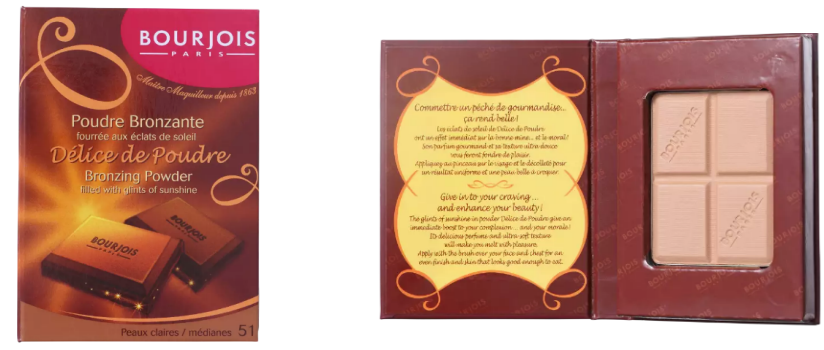
a. Não
b. Sim

b1. O fato dele ser aromatizado com cheiro de chocolate influenciou sua compra?

i. Sim, só comprei pelo cheiro.

ii. Não, mas o cheiro é um diferencial que me agrada.

iii. Não gosto do cheiro mas gosto do produto.

iv. Indiferente.

15. Qual a probabilidade de você comprar o produto abaixo?

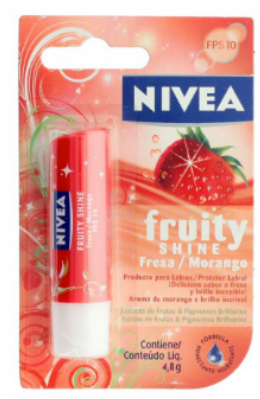
a. Certamente ou praticamente certo
b. Quase que com certeza
c. Muito provável 
d. Provável

e. Boa possibilidade

f. Razoável possibilidade

g. Alguma possibilidade

h. Pequena possibilidade

i. Escassa possibilidade

j. Probabilidade insignificante

k. Nenhuma chance ou quase nenhuma chance

16. Qual a probabilidade de você comprar o produto abaixo?

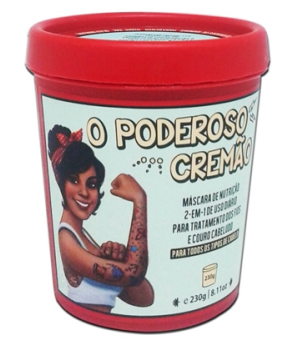

a. Certamente ou praticamente certo

b. Quase que com certeza

c. Muito provável

d. Provável

e. Boa possibilidade

f. Razoável possibilidade

g. Alguma possibilidade

h. Pequena possibilidade

i. Escassa possibilidade

j. Probabilidade insignificante

k. Nenhuma chance ou quase nenhuma chance 


\section{Anexo 2 - Questionário online}

1. O que te chama mais atenção dentro de uma loja especializada em produtos de beleza? (Marque quantas alternativas quiser)
a. Ambiente da loja
b. Exposição dos produtos
c. Variedade de produtos
d. Espaço para circulação de clientes
e. Exposição dos preços cobrados
f. Outro:

2. Onde você costuma comprar produtos voltados para beleza?

a. Lojas físicas (Sephora, MAC, Farmácias..)

b. Online

3. Complete a frase: costumo comprar produtos de beleza: (marque quantas alternativas quiser)
a. Por necessidade
b. Por vaidade
c. Por influência
d. Para presentear alguém
e. Para aproveitar uma promoção

4. O que você leva em conta na hora de escolher uma maquiagem? (numerar por ordem de importância)

Preço
Embalagem
Marca
Indicação
Custo benefício


5. Complete a frase: costumo entrar em lojas especializadas em beleza (ex: SEPHORA, The Beauty Box, MAC, Clinique, O Boticário): (marque quantas alternativas quiser)
a. Quando preciso comprar produtos
b. Para experimentar produtos
c. Para descobrir checar os lançamentos
d. Pelos serviços oferecidos (cursos de maquiagem, serviços de sobrancelha etc)
e. Pela ambiente

6. Você já deixou de comprar em alguma loja por alguns dos motivos abaixo?
a. Música alta
b. Falta de iluminação
c. Cheiro forte
d. Mau cheiro
e. Falta de organização
f. Mau atendimento
g. Preço elevado
h. Nenhum dos motivos anteriores

7. Em relação aos 5 sentidos qual você acredita mais usar na hora de escolher uma maquiagem?
a. Visão
b. Olfato
c. Paladar
d. Tato
e. Audição

8. Você acredita que o tipo de música tocado na loja influencia no seu comportamento de compra?

a. Sim, dependendo do tipo da música me sinto mais impulsivo a comprar ou não.

b. Indiferente, percebo certa influência mas não o suficiente para influenciar meu comportamento

c. Não percebo influência da musica sobre meu comportamento

9. Na sua opinião, a utilização de eventos com música e degustações como forma de lançar e promover um produto é:

a. Desnecessário, compraria o produto independentemente 
b. Desnecessário, mas acredito que agrega valor ao produto

c. Necessário, pois desperta sua curiosidade para querer conhecer o produto

d. Indispensável, se não fosse por essa experiência não compraria o produto

10. Uma loja está promovendo uma experimentação de um produto, o qual você não pensava em comprar mas é levado a experimentar e gosta bastante. Qual a probabilidade de comprar esse produto?
a. Certamente ou praticamente certo
b. Quase que com certeza
C. Muito provável
d. Provável
e. Boa possibilidade
f. Razoável possibilidade
g. Alguma possibilidade
h. Pequena possibilidade
i. Escassa possibilidade
j. Probabilidade insignificante

k. Nenhuma chance ou quase nenhuma chance

11. Você entra em uma loja para comprar um produto que precisa, qual a probabilidade de acabar sendo influenciada e levar mais alguma outra coisa?
a. Certamente ou praticamente certo
b. Quase que com certeza
C. Muito provável
d. Provável
e. Boa possibilidade
f. Razoável possibilidade
g. Alguma possibilidade
h. Pequena possibilidade
i. Escassa possibilidade
j. Probabilidade insignificante
k. Nenhuma chance ou quase nenhuma chance

12. Qual a importância de um perfume ter um provador (tester) na hora da compra?
a. Muito importante
b. Importante
c. Razoavelmente importante 

d. Pouco importante
e. Indiferente

13. Qual a importância de uma maquiagem ter um provador (tester) na hora da compra?
a. Muito importante
b. Importante
c. Razoavelmente importante
d. Pouco importante
e. Indiferente

14. Você já utilizou ou já ouvir falar do produto da foto?
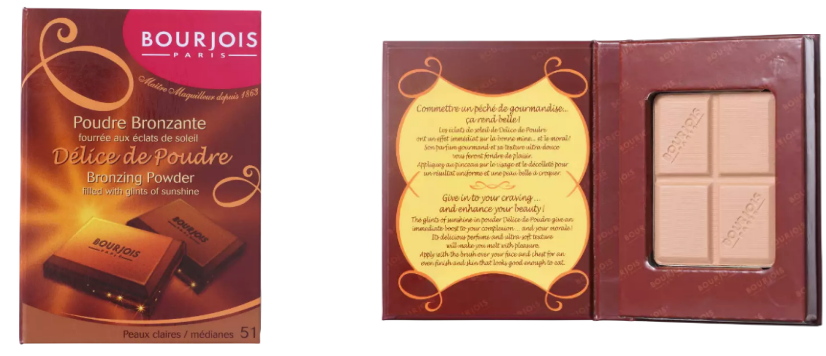
a. Não
b. Sim

b1. O fato dele ser aromatizado com cheiro de chocolate influenciou sua compra?

i. Sim, só comprei pelo cheiro.

ii. Não, mas o cheiro é um diferencial que me agrada.

iii. Não gosto do cheiro mas gosto do produto.

iv. Indiferente.

15. Qual a probabilidade de você comprar o produto abaixo?

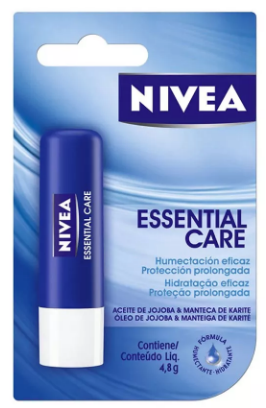
a. Certamente ou praticamente certo
b. Quase que com certeza
c. Muito provável 
d. Provável

e. Boa possibilidade

f. Razoável possibilidade

g. Alguma possibilidade

h. Pequena possibilidade

i. Escassa possibilidade

j. Probabilidade insignificante

k. Nenhuma chance ou quase nenhuma chance

16. Qual a probabilidade de você comprar o produto abaixo?

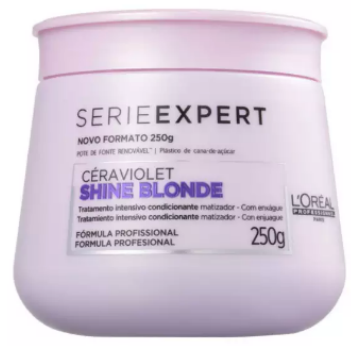

a. Certamente ou praticamente certo

b. Quase que com certeza

c. Muito provável

d. Provável

e. Boa possibilidade

f. Razoável possibilidade

g. Alguma possibilidade

h. Pequena possibilidade

i. Escassa possibilidade

j. Probabilidade insignificante

k. Nenhuma chance ou quase nenhuma chance 